\title{
The effect of a preparation of minerals, vitamins and trace elements on the cardiac gene expression pattern in male diabetic rats
}

Márta Sárközy ${ }^{1 \dagger}$, Gergő Szűcs ${ }^{1 \dagger}$, Márton Pipicz ${ }^{1}$, Ágnes Zvara ${ }^{2}$, Katalin Éder ${ }^{3}$, Veronika Fekete ${ }^{1}$, Csilla Szűcs ${ }^{4}$, Judit Bárkányi ${ }^{4}$, Csaba Csonka ${ }^{1}$, László G. Puskás², Csaba Kónya ${ }^{4}$, Péter Ferdinandy ${ }^{5,6+}$ and Tamás Csont ${ }^{1 *}$

\begin{abstract}
Background: Diabetic patients have an increased risk of developing cardiovascular diseases, which are the leading cause of death in developed countries. Although multivitamin products are widely used as dietary supplements, the effects of these products have not been investigated in the diabetic heart yet. Therefore, here we investigated if a preparation of different minerals, vitamins, and trace elements (MVT) affects the cardiac gene expression pattern in experimental diabetes.

Methods: Two-day old male Wistar rats were injected with streptozotocin (i.p. $100 \mathrm{mg} / \mathrm{kg}$ ) or citrate buffer to induce diabetes. From weeks 4 to 12, rats were fed with a vehicle or a MVT preparation. Fasting blood glucose measurement and oral glucose tolerance test were performed at week 12, and then total RNA was isolated from the myocardium and assayed by rat oligonucleotide microarray for 41012 oligonucleotides.

Results: Significantly elevated fasting blood glucose concentration and impaired glucose tolerance were markedly improved by MVT-treatment in diabetic rats at week 12. Genes with significantly altered expression due to diabetes include functional clusters related to cardiac hypertrophy (e.g. caspase recruitment domain family, member 9; cytochrome P450, family 26, subfamily B, polypeptide; FXYD domain containing ion transport regulator 3), stress response (e.g. metallothionein 1a; metallothionein 2a; interleukin-6 receptor; heme oxygenase (decycling) 1; and glutathione S-transferase, theta 3), and hormones associated with insulin resistance (e.g. resistin; FK506 binding protein 5; galanin/GMAP prepropeptide). Moreover the expression of some other genes with no definite cardiac function was also changed such as e.g. similar to apolipoprotein L2; brain expressed X-linked 1; prostaglandin b2 synthase (brain). MVT-treatment in diabetic rats showed opposite gene expression changes in the cases of 19 genes associated with diabetic cardiomyopathy. In healthy hearts, MVT-treatment resulted in cardiac gene expression changes mostly related to immune response (e.g. complement factor $B$; complement component 4a; interferon regulatory factor 7; hepcidin).
\end{abstract}

Conclusions: MVT-treatment improved diagnostic markers of diabetes. This is the first demonstration that MVTtreatment significantly alters cardiac gene expression profile in both control and diabetic rats. Our results and further studies exploring the mechanistic role of individual genes may contribute to the prevention or diagnosis of cardiac complications in diabetes.

Keywords: Diabetes mellitus, Haemoglobin A1c, Insulin resistance, Multivitamin, Heart, DNA microarray, Cardiac hypertrophy, Fibrosis, Oxidative/nitrative stress

\footnotetext{
* Correspondence: csont.tamas@med.u-szeged.hu

${ }^{\dagger}$ Equal contributors

'Department of Biochemistry, Faculty of Medicine, University of Szeged,

Szeged, Hungary

Full list of author information is available at the end of the article
} 


\section{Background}

In 2014, the global prevalence of diabetes mellitus (DM) was estimated to be $9 \%$ among adults aged over 18 years [1] reaching epidemic rates in the 21st century [2]. The number of patients diagnosed with DM is continuously increasing due to the increasing prevalence of hyperlipidaemia, visceral obesity and physical inactivity worldwide [2-4]. The total number of people suffering from DM is projected to rise to 552 million in 2030 [5].

Regular consumption of complex preparations containing various vitamins, minerals, and trace elements (MVT) is common in developed countries [6] to maintain general health. In the USA, for instance, more than half of the adult population use dietary supplements $[7,8]$, primarily in the form of multivitamins with or without minerals $[9,10]$. In 1998 a study reported that in Germany $18 \%$ of men and $25 \%$ of women were regular consumers of multivitamins among 18-79 years old adults [11]. Moreover, MVT preparations appeared on the market as medical food for patients suffering from metabolic diseases including hyperlipidaemia, metabolic syndrome, and DM. However, the literature is limited and controversial on the potential beneficial effects of these complex preparations containing more than 3 components on disease progression [12-16]. We have recently shown that chronic treatment with a MVT preparation improved well-established diagnostic markers of DM such as fasting blood glucose, HbA1c, glucose tolerance, and serum insulin levels in male diabetic rats [14].

It is well known that diabetic patients have an increased risk of developing cardiovascular diseases including diabetic cardiomyopathy [17]. Cardiovascular complications are estimated to be responsible for more than $50 \%$ of deaths among this population [18]. To explain the development of cardiovascular complications, the effect of DM on the cardiac gene expression pattern was investigated in a few studies [19-22]. In addition, we have previously shown that metabolic syndrome, which is a precursor state of type $2 \mathrm{DM}$, alters cardiac gene expression pattern in male ZDF rats [23]. However, the effect of MVT preparations on the cardiac gene expression pattern either in healthy or in diabetic condition has not yet been investigated.

Therefore, here we aimed at investigating the effects of a MVT preparation containing 26 different minerals, vitamins and vitamin-like antioxidants, as well as trace elements on the cardiac gene expression pattern in male diabetic rats.

\section{Materials and methods}

\section{Animals}

This investigation conforms to the National Institutes of Health Guide for the Care and Use of Laboratory Animals (NIH Pub. No. 85-23, Revised 1996) and was approved by the Animal Research Ethics Committee of the University of Szeged.

Two-day old neonatal male Wistar rats were used in this study. Lactating females with their litters were separately housed in individually ventilated cages (Sealsafe IVC system, Italy) and were maintained in a temperaturecontrolled room using 12:12 h light:dark cycles for 4 weeks. After separation from the mother at week 4, males were fed with standard rat chow (Additional file 1) and housed in pairs under the same circumstances as mentioned above until 12 weeks of age.

The injection of neonatal rats with streptozotocin (STZ) is a well characterized and recognized model of diabetes mellitus [24-27]. This model has been particularly characterized in detail in our previous study [14]. STZ is toxic especially to pancreatic $\beta$-cells. In contrast to injection of STZ to adult rats in a lower dose $(60 \mathrm{mg} / \mathrm{kg})$ that leads to type 1 diabetes with severe hyperglycemia [14, 24-27], administration of STZ to neonatal rats in a higher dose (90-100 mg/kg) leads to acute hyperglycemia within the first few days without resulting in complete loss of insulin production [14, 24-27]. According to literature data, after 5-6 weeks, the surviving rats develop characteristic symptoms of type 2 diabetes mellitus including dyslipidemia, hyperglycemia, impaired glucose tolerance and insulin resistance due to decreased $\beta$-cell mass [14, 24-27]. After 10-12 weeks, cardiovascular complications including hypertension and LV hypertrophy with decreased cardiac function are present in neonatal STZ-treated rats [28-34]. Therefore, this model is an appropriate choice to perform anti-diabetic drug screening studies.

\section{Experimental protocol}

Two days old neonatal male Wistar rats were intraperitoneally injected with $100 \mathrm{mg} / \mathrm{kg}$ of STZ $(n=25)$ or its vehicle (ice-cold citrate buffer, $n=16$ ) to induce experimental DM as described earlier [14].

At week 4, fasting blood glucose (FBG) measurement followed by an oral glucose tolerance test (OGTT) were performed in order to verify the development of impaired glucose tolerance in DM in surviving animals (data not shown). Mortality rates were $0 \%$ and $36 \%$ in citrate buffer-treated and in the STZ-treated group, respectively. Both citrate buffer-treated $(n=16)$ and STZtreated rats $(n=16)$ were then supplemented per os via gavage $(1 \mathrm{~mL} / \mathrm{kg}, 1 \%$ methylcellulose suspension) with a MVT preparation $(253.3 \mathrm{mg} / \mathrm{kg} / \mathrm{day}$, suspended in methylcellulose, $n=8-8)$ or its vehicle $(157 \mathrm{mg} / \mathrm{kg} /$ day, suspended in methylcellulose, $n=8-8$ ) for 8 weeks as described previously [14]. The MVT preparation administered in the present study is a registered medical food for human use (Diacomplex film-coated tablet, Béres Pharmaceuticals, Budapest, Hungary; for content see 
Table 1). To conform to the human daily dose of the preparation, the daily rat dose was adjusted according to the ratio of human and rat body surface areas as described previously [14]. Body weight was monitored every week. FBG, haemoglobin A1c level measurement and OGTT were performed at week 12 to assess the effect of MVT-treatment on DM. Serum insulin measurements were performed at week 4,8 and 12 in order to monitor the insulin secretion of pancreatic beta cells and the effect of MVT-treatment on the severity of pancreatic beta cell damage due to STZ-treatment. At week 12 , the rats were anaesthetized using pentobarbital (Euthasol, i.p. $50 \mathrm{mg} / \mathrm{kg}$; Produlab Pharma b.v., Raamsdonksveer, The Netherlands) [35]. Hearts and pancreata were isolated, and then the hearts were perfused according to Langendorff as described earlier [36, 37]. Coronary flow was measured during the ex vivo perfusion protocol [35]. After $10 \mathrm{~min}$ perfusion, ventricular tissue was frozen and stored at $-80{ }^{\circ} \mathrm{C}$ until DNA microarray investigation and gene expression analysis could be performed. Pancreata were removed, trimmed free of adipose tissue, then frozen and stored for pancreatic insulin content determination as described previously [23].

\section{FBG measurements and OGTT}

Rats were fasted overnight (12 h) prior to blood glucose level measurement and OGTT (week 12) in order to verify the development of DM and to monitor the effect of MVT-treatment on the progression of DM as described previously [14]. Briefly, blood samples were collected from the saphenous vein and blood glucose levels were measured using Accucheck blood glucose monitoring systems (Roche Diagnostics Corporation, USA, Indianapolis) $[14,23]$. After measurement of baseline glucose concentrations, glucose at $1.5 \mathrm{~g} / \mathrm{kg}$ body weight was administered via oral gavage and plasma glucose levels were measured 30, 60 and 120 minutes later during OGTT $[14,23]$.

Table 1 Ingredients of the MVT preparation

\begin{tabular}{|c|c|c|}
\hline Active ingredients & Amount of ingredient/1 g product & Daily dose ${ }^{a}$ \\
\hline Vitamin $A_{1}$ (Retinol) & 329 mg/g (109700 IU/g) & $83.3 \mu \mathrm{g} / \mathrm{kg} /$ day $(278 \mathrm{IU} / \mathrm{kg} /$ day $)$ \\
\hline Vitamin $B_{1}$ (Thiamin) & $2.30 \mathrm{mg} / \mathrm{g}$ & $0.58 \mathrm{mg} / \mathrm{kg} /$ day \\
\hline Vitamin $B_{2}$ (Riboflavin) & $2.63 \mathrm{mg} / \mathrm{g}$ & $0.67 \mathrm{mg} / \mathrm{kg} /$ day \\
\hline Vitamin $B_{3}$ (Nicotinamide) & $11.8 \mathrm{mg} / \mathrm{g}$ & $2.99 \mathrm{mg} / \mathrm{kg} /$ day \\
\hline Vitamin $B_{5}$ (Pantothenic acid) & $3.95 \mathrm{mg} / \mathrm{g}$ & $1.00 \mathrm{mg} / \mathrm{kg} /$ day \\
\hline Vitamin $B_{6}$ (Pyridoxine) & $3.29 \mathrm{mg} / \mathrm{g}$ & $0.83 \mathrm{mg} / \mathrm{kg} / \mathrm{day}$ \\
\hline Vitamin $B_{12}$ (Cyanocobalamin) & $3 \mu \mathrm{g} / \mathrm{g}$ & $0.76 \mu \mathrm{g} / \mathrm{kg} /$ day \\
\hline Folic acid & $197 \mu \mathrm{g} / \mathrm{g}$ & $49.9 \mu \mathrm{g} / \mathrm{kg} /$ day \\
\hline Biotin & $99 \mu \mathrm{g} / \mathrm{g}$ & $25.1 \mu \mathrm{g} / \mathrm{kg} /$ day \\
\hline Vitamin $D_{3}$ (Cholecalciferol) & $3 \mu \mathrm{g} / \mathrm{g}(120 \mathrm{IU} / \mathrm{g})$ & $0.76 \mu \mathrm{g} / \mathrm{kg} /$ day $(30.4 \mathrm{IU} / \mathrm{kg} /$ day) \\
\hline Vitamin $\mathrm{K}_{1}$ (Phyllokinone) & $26 \mu \mathrm{g} / \mathrm{g}$ & $6.59 \mu \mathrm{g} / \mathrm{kg} /$ day \\
\hline Rutoside & $3.29 \mathrm{mg} / \mathrm{g}$ & $0.83 \mathrm{mg} / \mathrm{kg} / \mathrm{day}$ \\
\hline Vitamin C & $65.8 \mathrm{mg} / \mathrm{g}$ & $16.7 \mathrm{mg} / \mathrm{kg} /$ day \\
\hline Vitamin E & $32.9 \mathrm{mg} / \mathrm{g}$ & $8.33 \mathrm{mg} / \mathrm{kg} / \mathrm{day}$ \\
\hline Lutein & $1.97 \mathrm{mg} / \mathrm{g}$ & $0.50 \mathrm{mg} / \mathrm{kg} / \mathrm{day}$ \\
\hline Chrome & $39 \mu \mathrm{g} / \mathrm{g}$ & $9.88 \mu \mathrm{g} / \mathrm{kg} /$ day \\
\hline Zinc & $9.87 \mathrm{mg} / \mathrm{g}$ & $2.50 \mathrm{mg} / \mathrm{kg} /$ day \\
\hline Selenium & $26 \mu \mathrm{g} / \mathrm{g}$ & $6.59 \mu \mathrm{g} / \mathrm{kg} /$ day \\
\hline Iron & $2.63 \mathrm{mg} / \mathrm{g}$ & $0.67 \mathrm{mg} / \mathrm{kg} / \mathrm{day}$ \\
\hline lodine & $66 \mu \mathrm{g} / \mathrm{g}$ & $16.7 \mu \mathrm{g} / \mathrm{kg} /$ day \\
\hline Manganese & $0.66 \mathrm{mg} / \mathrm{g}$ & $0.17 \mathrm{mg} / \mathrm{kg} / \mathrm{day}$ \\
\hline Copper & $921 \mu \mathrm{g} / \mathrm{g}$ & $233 \mu \mathrm{g} / \mathrm{kg} /$ day \\
\hline Molybdenum & $49 \mu \mathrm{g} / \mathrm{g}$ & $12.4 \mu \mathrm{g} / \mathrm{kg} /$ day \\
\hline Magnesium & $65.8 \mathrm{mg} / \mathrm{g}$ & 16.7 mg/kg/day \\
\hline Calcium & $132 \mathrm{mg} / \mathrm{g}$ & $33.4 \mathrm{mg} / \mathrm{kg} /$ day \\
\hline Phosphorus & $102 \mathrm{mg} / \mathrm{g}$ & $25.8 \mathrm{mg} / \mathrm{kg} / \mathrm{day}$ \\
\hline
\end{tabular}

${ }^{a}$ To conform to the human daily dose of the preparation, rat daily dose was adjusted according to the ratio of human and rat body surface areas 


\section{Haemoglobin A1c measurement}

To monitor the effect of the MVT containing preparation on the severity of DM, haemoglobin A1c was measured from whole venous blood with an in vitro test (Bio-Rad in2it System) according to the instructions of the manufacturer [14]. The test is based on single wave length photometry $(440 \mathrm{~nm})$ to detect glycated fraction separated from the non-glycated fraction by boronate affinity chromatography [14].

\section{Measurement of serum and pancreatic insulin levels}

To monitor the effect of MVT-treatment on the severity of DM, serum and pancreatic insulin levels were measured by an enzyme immunoassay (Mercodia, Ultrasensitive Rat Insulin ELISA) in duplicates according to the manufacturer's instructions as described previously $[14,23]$.

\section{RNA preparation and DNA microarray analysis}

Total RNA was isolated from heart samples with Qiagen miRNeasy Mini Kit according to the manufacturer's protocol (Qiagen, Hilden, Germany). On-column DNase digestion was carried out with the RNase-Free DNase Set (Qiagen $\mathrm{GmbH}$ ). RNA concentration was measured by NanoDrop 1000 Spectrophotometer (Thermo Fisher Scientific Inc., Waltham, MA, USA) and RNA integrity was determined by an Agilent 2100 Bioanalyzer System (Agilent Technologies Inc., Santa Clara, CA, USA). Samples with an RNA integrity number (RIN) above 8.0 were used for further analysis. RNA was stored at $-80{ }^{\circ} \mathrm{C}$ until use.

Total RNA (200 ng) was labelled and amplified using the Low Input Quick Amp Labelling Kit according to the instructions of the manufacturer. Labelled RNA was purified and hybridized to Agilent Whole Rat Genome $4 \times 44 \mathrm{~K}$ array slides, according to the manufacturer's protocol. After washing, array scanning and feature extraction was performed with default scenario by Agilent DNA Microarray Scanner and Feature Extraction Software 11.01.

\section{Messenger RNA (mRNA) expression profiling by qRT-PCR} In order to validate gene expression changes obtained by DNA microarray, qRT-PCR was performed on a RotorGene 3000 instrument (Corbett Research, Sydney, Australia) with gene-specific primers and SybrGreen protocol to monitor gene expression as described earlier [23]. Briefly, $2 \mu \mathrm{g}$ of total RNA was reverse transcribed using the High-Capacity cDNA Archive Kit (Applied Biosystems Foster City, CA, USA) according to the manufacturer's instructions in a final volume of $30 \mu \mathrm{L}$. After dilution with $30 \mu \mathrm{L}$ of water, $1 \mu \mathrm{L}$ of the diluted reaction mix was used as a template in the qRT-PCR with FastStart SYBR Green Master mix (Roche Applied Science,
Mannheim, Germany) with the following protocol: $10 \mathrm{~min}$ at $95{ }^{\circ} \mathrm{C}$ followed by 45 cycles of $95{ }^{\circ} \mathrm{C}$ for $15 \mathrm{sec}, 60{ }^{\circ} \mathrm{C}$ for $25 \mathrm{sec}$ and $72{ }^{\circ} \mathrm{C}$ for $25 \mathrm{sec}$. The fluorescence intensity of SybrGreen dye was detected after each amplification step. Melting temperature analysis was done after each reaction to check the quality of the products. Primers were designed using the online Roche Universal Probe Library Assay Design Center. The quality of the primers was verified by MS analysis provided by Bioneer (Daejeon, Korea). Relative expression ratios were calculated as normalized ratios to rat HPRT and Cyclophyllin genes. A non-template control sample was used for each primer to check primer-dimer formation. The final relative gene expression ratios were calculated as delta-delta $\mathrm{Ct}$ values. Fold change refers to $2^{-\Delta \Delta C t}$ (in the case of up-regulated genes) and $-\left(1 / 2^{-\Delta \Delta C t}\right)$ (in the case of down-regulated genes).

\section{Statistical analysis}

Statistical analysis was performed by using Sigmaplot 12.0 for Windows (Systat Software Inc). All values are presented as mean \pm SEM. Two-Way ANOVA was used to determine the effect of DM or MVT on body weight, FBG, glucose levels during OGTT, OGTT AUC, HbA1c, serum and pancreatic insulin concentrations, pancreas weight and coronary flow. After ANOVA, all pairwise multiple comparison procedures with Holm-Šídák post hoc tests were used as multiple range tests. $P<0.05$ was accepted as a statistically significant difference.

In the microarray experiments, biological and technical replica tests were carried out to gain raw data for statistical analysis. Altogether 9 individual parallel gene activity comparisons were done between two groups. Both in the microarray and qRT-PCR experiments, a two-sample $t$-test was used and the $\mathrm{p}$ value was determined to find significant gene expression changes in 3 separate comparisons. In the microarray experiments, a corrected $\mathrm{p}$ value was determined for each gene to control the false discovery rate using the Benjamini and Hochberg multiple testing correction protocol. Gene expression ratios with $\mathrm{p}$ value of $<0.05$ and $\log _{2}$ ratio of $<-0.85$ or $\log _{2}$ ratio of $>0.85(\sim 1.8$ fold change) were considered as repression or overexpression respectively in gene activity.

\section{Results}

Characterization of experimental DM and the effects of MVT-treatment on the progression of DM

The time dependence of development of DM in neonatal STZ-treated rats in both genders has been particularly characterized in detail in our previous study [14]. In the present study, concentrations of several plasma metabolites and body weight were measured in order to verify the development of DM in the STZ-treated rats (Fig. 1). OGTT showed increased glucose levels at every time 

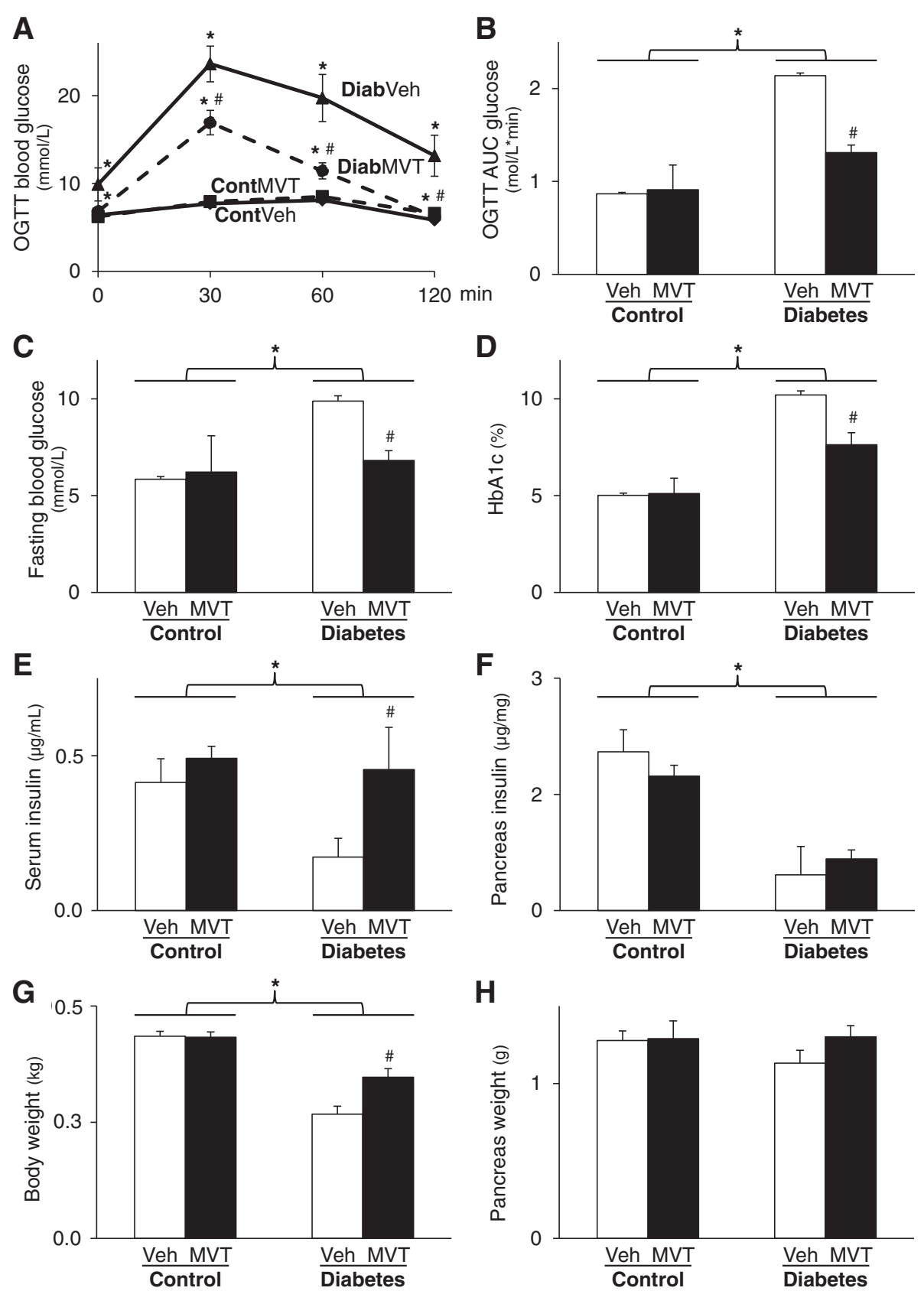

Fig. 1 Characterization of experimental DM and the effects of MVT-treatment on the progression of DM. a Blood glucose levels during oral glucose tolerance test (OGTT) and $\mathbf{b}$ its area under the curve (AUC). $\mathbf{c}$ Level of fasting blood glucose and $\mathbf{d}$ haemoglobin A1c. e Serum and $\mathbf{f}$ pancreas insulin. $\mathbf{g}$ Body and $\mathbf{h}$ pancreas weight. Values are expressed as mean \pm S.E.M. ${ }^{*} p<0.05$ vs. control, $\# p<0.05$ vs. diabetes vehicle, two-way ANOVA, $\mathrm{n}=8$ in each group. Cont $=$ Control, Diab $=$ Diabetes, Veh $=$ Vehicle, MVT = preparation of minerals, vitamins, and trace elements

point following oral glucose load accompanied with increased area under the curve (AUC) values in STZtreated groups showing impaired glucose tolerance (Fig. 1a and b). MVT-treatment significantly decreased glucose and OGTT AUC values in the STZ-treated groups, proving an anti-diabetic effect of the MVT preparation (Fig. 1a and b). FBG level was significantly higher in STZ-treated groups as compared to the control group showing the development of DM (Fig. 1c). However, FBG level was significantly decreased by MVT-treatment in the STZ-treated diabetic group (Fig. 1c). HbA1c level was significantly increased in STZ-treated groups as compared to controls (Fig. 1d) demonstrating chronic hyperglycaemia and the development of DM. Interestingly, MVT-treatment significantly reduced the HbA1c level in the STZ-treated diabetic group (Fig. 1d). Serum 
Table 2 Genes significantly down-regulated in diabetes vehicle-treated vs. control vehicle-treated group on DNA microarray

\begin{tabular}{|c|c|c|c|c|c|c|c|c|c|c|}
\hline \multirow[b]{4}{*}{ Gene function } & \multirow[b]{4}{*}{ Gene Name provided by $R G D^{a}$} & \multirow[b]{4}{*}{ Acc. Number } & \multirow[b]{4}{*}{ Gene Symbol } & \multirow{3}{*}{\multicolumn{3}{|c|}{$\begin{array}{l}\text { Diabetes Vehicle } \\
\text { vs. } \\
\text { Control Vehicle }\end{array}$}} & \multirow{3}{*}{\multicolumn{2}{|c|}{$\begin{array}{l}\text { Diabetes MVT } \\
\text { vs. } \\
\text { Diabetes Vehicle }\end{array}$}} & \multirow{3}{*}{\multicolumn{2}{|c|}{$\begin{array}{l}\text { Control MVT } \\
\text { vs. } \\
\text { Control Vehicle }\end{array}$}} \\
\hline & & & & & & & & & & \\
\hline & & & & & & & & & & \\
\hline & & & & $\log _{2}(\mathrm{SD})$ & Corr. $p$ & Fold change & $\log _{2}(\mathrm{SD})$ & Fold Change & $\log _{2}(\mathrm{SD})$ & Fold Change \\
\hline Metabolism & $\begin{array}{l}\text { UDP-Gal:betaGIcNAc beta } \\
\text { 1,3-galactosyltransferase, polypeptide } 2\end{array}$ & NM_001109492 & B3galt2 & $-1.14(0.19)$ & 0.003 & -2.21 & $0.80(0.49)$ & 1.74 & $-0.16(0.60)$ & -1.11 \\
\hline Metabolism & adenylate kinase 4 & NM_017135 & Ak4 & $-0.99(0.49)$ & 0.026 & -1.99 & $0.76(0.40)$ & 1.70 & $-0.47(0.70)$ & -1.38 \\
\hline Stress response & $\begin{array}{l}\text { APEX (apurinic/apyrimidinic) } \\
\text { endonuclease } 2\end{array}$ & NM_001079892 & Apex2 & $-0.94(0.56)$ & 0.042 & -1.92 & $0.09(0.26)$ & 1.06 & $-1.18(0.63)$ & -2.26 \\
\hline Apoptosis/necrosis and inflammation & $\begin{array}{l}\text { caspase recruitment domain family, } \\
\text { member } 9\end{array}$ & NM_022303 & Card9 & $-2.74(0.64)$ & 0.003 & -6.69 & $1.82(0.52)$ & 3.53 & $-1.20^{b}(0.88)$ & -2.29 \\
\hline Apoptosis/necrosis and inflammation & chemokine (C-X-C motif) ligand 12 & NM_001033883 & $\mathrm{CxCl12}$ & $-0.86(0.38)$ & 0.021 & -1.82 & $0.48(0.40)$ & 1.40 & $0.06(0.30)$ & 1.04 \\
\hline Cell growth and differentiation & neuronal regeneration related protein & NM_178096 & Nrep & $-1.11(0.55)$ & 0.023 & -2.46 & $0.50(0.49)$ & 1.41 & $-1.46^{b}(1.36)$ & -2.74 \\
\hline Cell growth and differentiation & HOP homeobox & NM_133621 & Hopx & $-1.14(0.52)$ & 0.020 & -2.20 & $0.60(0.49)$ & 1.51 & $-0.28(0.71)$ & -1.21 \\
\hline Cell growth and differentiation & fibroblast growth factor 18 & NM_019199 & Fgf18 & $-1.12(0.53)$ & 0.021 & -2.17 & $0.80(0.57)$ & 1.74 & $-0.51(0.23)$ & -1.43 \\
\hline Cell growth and differentiation & ret proto-oncogene & NM_012643 & Ret & $-1.04(0.14)$ & 0.003 & -2.06 & $0.63(0.39)$ & 1.55 & $-0.63(0.15)$ & -1.55 \\
\hline Cell growth and differentiation & G0/G1 switch 2 & NM_001009632 & GOs2 & $-0.86(0.21)$ & 0.007 & -1.82 & $0.58(0.47)$ & 1.50 & $0.26(0.91)$ & 1.20 \\
\hline Receptors and ion channels & adrenoceptor alpha 1D & NM_024483 & Adrald & $-1.21(0.52)$ & 0.016 & -2.31 & $1.12(0.40)$ & 2.17 & $-1.03^{b}(1.36)$ & -2.04 \\
\hline Receptors and ion channels & $\begin{array}{l}\text { FXYD domain-containing ion transport } \\
\text { regulator } 3\end{array}$ & NM_172317 & Fxyd3 & $-1.01(0.49)$ & 0.023 & -2.01 & $1.97(0.48)$ & 3.92 & $-0.36(0.85)$ & -1.29 \\
\hline Receptors and ion channels & $\begin{array}{l}\text { sodium channel, voltage-gated, } \\
\text { type IV, beta }\end{array}$ & NM_001008880 & $\operatorname{Scn} 4 b$ & $-0.94(0.30)$ & 0.011 & -1.92 & $0.38(0.15)$ & 1.30 & $-0.43(0.49)$ & -1.35 \\
\hline Receptors and ion channels & transferrin receptor & NM_022712 & Tfre & $-0.87(0.21)$ & 0.007 & -1.83 & $0.09(0.20)$ & 1.06 & $-0.55(0.32)$ & -1.46 \\
\hline Structural protein, cell adhesion & myosin binding protein C, fast-type & NM_001106257 & Mybpc2 & $-0.93(0.47)$ & 0.026 & -1.90 & $0.33(0.52)$ & 1.25 & $0.48(0.82)$ & 1.40 \\
\hline Structural protein, cell adhesion & protocadherin 17 & NM_001107279 & Pcdh17 & $-0.94(0.44)$ & 0.023 & -1.91 & $0.90(0.43)$ & 1.86 & $-0.65(0.43)$ & -1.57 \\
\hline Hormones & inhibin alpha & NM_012590 & Inha & $-0.89(0.39)$ & 0.020 & -1.85 & $1.59(0.79)$ & 3.01 & $0.66(0.21)$ & 1.58 \\
\hline Transport & globin, alpha & NM_001013853 & LOC287167 & $-1.64(0.72)$ & 0.015 & -3.12 & $-0.23(0.81)$ & -1.18 & $-1.80(0.76)$ & -3.47 \\
\hline Transport & haemoglobin, beta adult major chain & NM_198776 & $H b b-b 1$ & $-1.94(0.75)$ & 0.011 & -3.83 & $-0.40(0.77)$ & -1.32 & $-2.23(0.76)$ & -4.71 \\
\hline Transport & alpha-2u globulin PGCL5 & NM_147213 & LOC259245 & $-0.87(0.54)$ & 0.047 & -1.83 & $-0.03(0.48)$ & -1.02 & $-0.12(0.58)$ & -1.08 \\
\hline Others & uncharacterized LOC100909684 & XR_146107 & LOC10099684 & $-3.07(1.43)$ & 0.016 & -8.43 & $2.55(1.40)$ & 5.85 & $-0.42(0.76)$ & -1.34 \\
\hline Others & uncharacterized LOC100910110 & XR_146304 & LOC100910110 & $-1.94(0.32)$ & 0.003 & -3.85 & $2.32(0.31)$ & 5.01 & $-0.46(1.57)$ & -1.38 \\
\hline
\end{tabular}

Values show gene expression. $\log _{2}$ ratio reaching at least \pm 0.85 and $p<0.05$ were considered as significant alterations

${ }^{2}$ RGD: rat genome database

bon significant change $(p>0.05)$ 
insulin levels were significantly decreased in the STZinjected vehicle-treated group as compared to control vehicle-treated group both at week $4(0.05 \pm 0.01$ vs. $0.16 \pm 0.02 \mu \mathrm{g} / \mathrm{mL})$ and $8(0.08 \pm 0.02$ vs. $0.17 \pm 0.02 \mu \mathrm{g} /$ $\mathrm{mL}$ ) proving deteriorated pancreatic beta cell function in DM. MVT-treatment had no significant effect on serum insulin levels at weeks 4 and 8 in diabetic $(0.06 \pm 0.01$ and $0.12 \pm 0.03 \mu \mathrm{g} / \mathrm{mL}$, respectively) and control animals $(0.12 \pm 0.02$ and $0.25 \pm 0.03 \mu \mathrm{g} / \mathrm{mL})$ when compared to appropriate vehicle-treated controls. At week 12, serum and pancreatic insulin concentration were significantly decreased in STZ-treated diabetic animals, proving pancreatic $\beta$-cell damage (Fig. 1e and f). MVT-treatment showed a significant increase in serum insulin concentrations in STZ-treated animals (Fig. 1e). However, MVT-treatment failed to significantly improve pancreatic insulin content in STZ-treated diabetic animals (Fig. 1f). In addition, body weight gain of STZ-treated rats was significantly lower as compared to control rats. However, weight gain was significantly improved by the MVT-treatment in the STZ-treated group (Fig. 1g). Neither DM nor MVT-treatment had a significant effect on pancreas weight (Fig. 1h). Coronary flow was significantly lower in the diabetic vehicletreated group as compared to the control vehicletreated group $(16.4 \pm 2.04$ vs. $19.25 \pm 0.48 \mathrm{~mL} / \mathrm{min})$ showing impaired cardiac function in diabetic hearts. However, MVT-treatment failed to improve coronary flow in the diabetic group $(17.0 \pm 0.52 \mathrm{~mL} / \mathrm{min})$ and had no significant effect in the control group either $(19.29 \pm 0.94 \mathrm{~mL} / \mathrm{min})$.

\section{Global cardiac gene expression changes}

To determine genes in 1) diabetic vehicle-treated, 2) diabetic MVT-treated, 3) control vehicle-treated and 4) control MVT-treated groups, total RNA isolation and then DNA microarray analysis were performed from the hearts of all groups. Among the 41012 rat oligonucleotides surveyed, 16752 oligonucleotides in diabetic vehicle-treated group, 17531 oligonucleotides in diabetic MVT-treated group, 17447 oligonucleotides in control vehicletreated group and 17184 oligonucleotides in control MVT-treated group showed expression.

\section{Identification of genes associated with DM}

To determine genes associated with DM and diabetic cardiomyopathy, cardiac gene expression induced in the diabetic vehicle-treated group was compared with the control vehicle-treated group (Tables 2 and 3). In diabetic vehicle-treated hearts, 37 genes showed significant up-regulation and 22 genes showed significant downregulation (Tables 2 and 3 ).

\section{Identification of genes associated with MVT-treatment in DM}

To determine genes associated with the effects of MVTtreatment in diabetic hearts, cardiac gene expression induced in the diabetic MVT-treated group was compared with the diabetic vehicle-treated group (Tables 4 and 5). In diabetic MVT-treated hearts, 15 genes showed significant up-regulation and 29 genes showed significant down-regulation, compared to diabetic vehicle-treated controls (Tables 4 and 5). In the diabetic MVT-treated group, an additional 23 genes were found, which expression pattern was significantly influenced only by the MVT-treatment. These 23 genes did not show significant gene expression change in the diabetic vehicletreated group as compared to the control vehicle-treated group (Tables 2 and 5). To assess potential beneficial effects of MVT-treatment, we analysed opposite gene expression changes in the diabetic MVT-treated group as compared to the diabetic vehicle-treated group. Among the oppositely altered genes in the diabetic MVT-treated group, 5 genes showed significant up-regulation and 14 genes showed significant down-regulation, respectively (Fig. 2). These 19 genes may be associated with potential cardioprotective effects of MVT-treatment in DM.

\section{Identification of genes associated with MVT-treatment in healthy condition}

To determine genes associated with the effects of MVTtreatment in healthy control hearts, cardiac gene expression induced in the control MVT-treated group was compared with the control vehicle-treated group (Tables 6 and 7). In control MVT-treated hearts, 18 genes showed significant up-regulation and 6 genes showed significant down-regulation (Tables 6 and 7). Out of these significantly altered 24 genes, 18 genes were not significantly altered in diabetic MVT-treated rats. These 18 genes may be associated with potential beneficial effects of MVTtreatment in healthy or diseased conditions.

\section{Validation of microarray data by qRT-PCR}

To confirm the microarray data we measured the expression of selected 5 genes by qRT-PCR in 2 different setups: 1) diabetes vehicle-treatment vs. control vehicletreatment groups and 2) diabetes MVT-treatment vs. diabetes vehicle-treatment groups (Tables 8 and 9). In both setups, the expression changes of 4 genes were confirmed by qRT-PCR and showed reliability of the microarray data.

\section{Discussion}

In the present study we have confirmed that chronic treatment with a MVT preparation attenuated the progression of DM by improving diagnostic markers of DM including glucose tolerance, FBG, HbA1c, and serum 
Table 3 Genes significantly up-regulated in diabetes vehicle-treated vs. control vehicle-treated group on DNA microarray

\begin{tabular}{|c|c|c|c|c|c|c|c|c|c|c|}
\hline \multirow[b]{4}{*}{ Gene function } & \multirow[b]{4}{*}{ Gene Name provided by $R G D^{a}$} & \multirow[b]{4}{*}{ Acc. Number } & \multirow[b]{4}{*}{ Gene Symbol } & \multirow{3}{*}{\multicolumn{3}{|c|}{$\begin{array}{l}\text { Diabetes Vehicle } \\
\text { vs. } \\
\text { Control Vehicle }\end{array}$}} & \multirow{3}{*}{\multicolumn{2}{|c|}{$\begin{array}{l}\text { Diabetes MVT } \\
\text { vs. } \\
\text { Diabetes Vehicle }\end{array}$}} & \multirow{3}{*}{\multicolumn{2}{|c|}{$\begin{array}{l}\text { Control MVT } \\
\text { vs. } \\
\text { Control Vehicle }\end{array}$}} \\
\hline & & & & & & & & & & \\
\hline & & & & & & & & & & \\
\hline & & & & $\log _{2}(S D)$ & Corr.p & Fold change & $\log _{2}(S D)$ & Fold Change & $\log _{2}(S D)$ & Fold Change \\
\hline Metabolism & $\begin{array}{l}\text { UDP-N-acetyl-alpha-D-galactosamine: } \\
\text { polypeptide } \\
\text { N-acetylgalactosaminyltransferase } 15\end{array}$ & XM_003752864 & Galnt15 & $0.85(0.53)$ & 0.047 & 1.81 & $-0.58(0.40)$ & -1.49 & $0.32(0.55)$ & 1.25 \\
\hline Metabolism & $\begin{array}{l}\text { microtubule associated } \\
\text { monooxygenase, calponin and } \\
\text { LIM domain containing } 1\end{array}$ & NM_001106397 & Micall & $0.89(0.23)$ & 0.007 & 1.86 & $-0.21(0.19)$ & -1.16 & $0.52(0.23)$ & 1.43 \\
\hline Metabolism & $\begin{array}{l}\text { proline dehydrogenase } \\
\text { (oxidase) } 1\end{array}$ & NM_001135778 & Prodh & $0.95(0.48)$ & 0.026 & 1.93 & $-0.27(0.63)$ & -1.21 & $0.93(0.50)$ & 1.91 \\
\hline Metabolism & 4-hydroxyphenylpyruvate dioxygenase & NM_017233 & Hpd & $1.07(0.38)$ & 0.011 & 2.09 & $-0.06(0.34)$ & -1.04 & $1.00(0.48)$ & 2.01 \\
\hline Stress response & glutathione S-transferase, theta 3 & NM_001137643 & Gstt3 & $0.88(0.52)$ & 0.042 & 1.84 & $-0.13(0.38)$ & -1.09 & $0.61(0.80)$ & 1.52 \\
\hline Stress response & heme oxygenase (decycling) 1 & NM_012580 & Hmox1 & $1.08(0.47)$ & 0.017 & 2.12 & $-0.62(0.49)$ & -1.54 & $0.52(0.25)$ & 1.43 \\
\hline Stress response & metallothionein 1a & NM_138826 & Mt1a & $1.32(0.34)$ & 0.005 & 2.49 & $-1.18(0.43)$ & -2.26 & $0.09(0.39)$ & 1.06 \\
\hline Stress response & metallothionein 2a & NM_001137564 & $M+2 a$ & $1.61(0.34)$ & 0.003 & 3.06 & $-1.70(0.66)$ & -3.24 & $0.24(0.53)$ & 1.18 \\
\hline Immune response & NLR family member $\mathrm{X} 1$ & NM_001025010 & Nirxl & $0.87(0.48)$ & 0.036 & 1.83 & $-1.07(0.43)$ & -2.10 & $0.30(0.43)$ & 1.23 \\
\hline Immune response & FK506 binding protein 5 & NM_001012174 & Fkbp5 & $1.13(0.52)$ & 0.020 & 2.19 & $-1.09(0.32)$ & -2.13 & $0.83(0.74)$ & 1.77 \\
\hline Immune response & influenza virus NS1A binding protein & NM_001047085 & Ivnslabp & $1.27(0.40)$ & 0.008 & 2.41 & $-0.65(0.35)$ & -1.57 & $0.68(0.79)$ & 1.60 \\
\hline Apoptosis/necrosis and inflammation & interleukin 6 receptor & NM_017020 & $116 r$ & $0.91(0.50)$ & 0.034 & 1.88 & $-1.00(0.47)$ & -2.00 & $0.63(0.67)$ & 1.54 \\
\hline Cell growth and differentiation & $\begin{array}{l}\text { H19, imprinted maternally } \\
\text { expressed transcript }\end{array}$ & NR_027324 & H19 & $0.92(0.49)$ & 0.032 & 1.89 & $-0.53(0.47)$ & -1.44 & $1.16(0.44)$ & 2.24 \\
\hline Cell growth and differentiation & secreted frizzled-related protein 2 & NM_001100700 & Sfrp2 & $1.22(0.73)$ & 0.039 & 2.34 & $-0.62(0.77)$ & -1.54 & $0.87^{b}(0.73)$ & 1.83 \\
\hline Cell growth and differentiation & $\begin{array}{l}\text { wingless-type MMTV integration } \\
\text { site family, member } 2 B\end{array}$ & NM_001191848 & $W n+2 b$ & $1.32(0.11)$ & 0.003 & 2.50 & $-1.66(0.48)$ & -3.15 & $0.16(0.11)$ & 1.11 \\
\hline Cell growth and differentiation & brain expressed, $X$-linked 1 & NM_001037365 & Bex1 & $1.41(0.30)$ & 0.003 & 2.65 & $-1.97(0.45)$ & -3.92 & $0.25(0.81)$ & 1.19 \\
\hline Cell growth and differentiation & $\mathrm{N}$-myc downstream regulated 1 & NM_001011991 & Ndrg1 & $0.85(0.42)$ & 0.027 & 1.81 & $-1.05(0.33)$ & -2.07 & $0.41(0.62)$ & 1.33 \\
\hline Receptors and ion channels & $\begin{array}{l}\text { solute carrier family } 26 \text { (anion } \\
\text { exchanger), member } 3\end{array}$ & NM_053755 & S/c26a3 & $0.88(0.34)$ & 0.015 & 1.84 & $-0.03(0.23)$ & -1.02 & $0.01(0.32)$ & 1.01 \\
\hline Receptors and ion channels & $\begin{array}{l}\text { ATPase, } \mathrm{H}^{+} \text {transporting, lysosomal } \\
\text { V1 subunit } \mathrm{G} 2\end{array}$ & NM_212490 & Atp6r1g2 & $0.92(0.41)$ & 0.020 & 1.89 & $-1.05(0.43)$ & -2.06 & $-0.75(0.22)$ & -1.68 \\
\hline Receptors and ion channels & $\begin{array}{l}\text { ATP-binding cassette, subfamily A } \\
\text { (ABC1), member } 1\end{array}$ & NM_178095 & Abcal & $1.01(0.35)$ & 0.011 & 2.01 & $-0.22(0.39)$ & -1.17 & $0.54(0.40)$ & 1.45 \\
\hline Receptors and ion channels & sarcolipin & NM_001013247 & $\sin$ & $1.07(0.61)$ & 0.036 & 2.10 & $-0.23(0.42)$ & -1.17 & $1.09(0.61)$ & 2.13 \\
\hline
\end{tabular}


Table 3 Genes significantly up-regulated in diabetes vehicle-treated vs. control vehicle-treated group on DNA microarray (Continued)

\begin{tabular}{|c|c|c|c|c|c|c|c|c|c|c|}
\hline $\begin{array}{l}\text { Signal transduction, regulation of } \\
\text { transcription }\end{array}$ & $\begin{array}{l}\text { zinc finger and BTB domain } \\
\text { containing } 16\end{array}$ & NM_001013181 & Zbtb16 & $0.89(0.29)$ & 0.011 & 1.85 & $-0.69(0.33)$ & -1.62 & $0.37(0.52)$ & 1.30 \\
\hline Signal transduction, regulation of transcription & $\begin{array}{l}\text { Rho-related BTB domain } \\
\text { containing } 1\end{array}$ & NM_001107622 & Rhobtb1 & $0.91(0.25)$ & 0.008 & 1.88 & $-0.22(0.25)$ & -1.16 & $0.58(0.55)$ & 1.49 \\
\hline Signal transduction, regulation of transcription & $\begin{array}{l}\text { connector enhancer of kinase } \\
\text { suppressor of Ras } 1\end{array}$ & NM_001039011 & Cnksr1 & $1.31(0.67)$ & 0.025 & 2.48 & $-1.64(0.38)$ & -3.13 & $0.39(0.72)$ & 1.31 \\
\hline $\begin{array}{l}\text { Signal transduction, regulation } \\
\text { of transcription }\end{array}$ & $\begin{array}{l}\text { cytochrome P450, family } 26 \text {, } \\
\text { subfamily b, polypeptide } 1\end{array}$ & NM_181087 & Cyp26b1 & $1.62(0.28)$ & 0.003 & 3.08 & $-1.68(0.47)$ & -3.20 & $0.25(0.30)$ & 1.19 \\
\hline Structural protein, cell adhesion & pannexin 2 & NM_199409 & Panx2 & $0.97(0.17)$ & 0.003 & 1.96 & $-0.56(0.33)$ & -1.47 & $0.81(0.15)$ & 1.75 \\
\hline Structural protein, cell adhesion & myosin light chain kinase 2 & NM_057209 & Mylk2 & $1.17(0.32)$ & 0.006 & 2.25 & $-0.05(0.37)$ & -1.03 & $1.05^{b}(0.69)$ & 2.08 \\
\hline Hormones & resistin & NM_144741 & Retn & $1.08(0.60)$ & 0.034 & 2.12 & $-1.03(0.44)$ & -2.05 & $0.51(0.96)$ & 1.43 \\
\hline Hormones & galanin/GMAP prepropeptide & NM_033237 & Gal & $2.41(1.15)$ & 0.018 & 5.31 & $-2.99(0.92)$ & -7.96 & $1.82^{b}(1.20)$ & 3.53 \\
\hline Hormones & natriuretic peptide $\mathrm{A}$ & NM_012612 & Nppa & $1.23(0.45)$ & 0.011 & 2.34 & $-0.62(0.42)$ & -1.54 & $0.79(0.38)$ & 1.73 \\
\hline Others & myosin binding protein $\mathrm{H}$-like & NM_001014042 & Mybphl & $1.26(0.75)$ & 0.038 & 2.39 & $-0.66(0.68)$ & -1.58 & $1.09^{b}(0.71)$ & 2.13 \\
\hline Others & prostaglandin D2 synthase (brain) & NM_013015 & Ptgds & $1.32(0.69)$ & 0.026 & 2.50 & $-0.64(0.46)$ & -1.56 & $0.67(0.87)$ & 1.59 \\
\hline Others & visinin-like 1 & NM_012686 & Vsn/1 & $1.49(0.79)$ & 0.026 & 2.80 & $-1.01^{b}(0.77)$ & -2.01 & $1.16^{b}(0.76)$ & 2.24 \\
\hline Others & transmembrane protein 140 & NM_001009709 & Tmem 140 & $1.49(0.27)$ & 0.003 & 2.80 & $-0.59(0.42)$ & -1.50 & $0.30(0.26)$ & 1.23 \\
\hline Others & $\begin{array}{l}\text { IQ motif and ubiquitin domain } \\
\text { containing }\end{array}$ & NM_001034130 & lqub & $0.94(0.36)$ & 0.014 & 1.91 & $0.23(0.20)$ & 42021 & $0.52(0.59)$ & 1.44 \\
\hline Others & $\begin{array}{l}\text { similar to apolipoprotein L2; } \\
\text { apolipoprotein L-II }\end{array}$ & NM_001134801 & RGD1309808 & $4.33(2.91)$ & 0.049 & 42358 & $-6.07(0.68)$ & -67.24 & $1.61^{b}(3.76)$ & 3.05 \\
\hline Others & $\begin{array}{l}\text { thioredoxin domain } \\
\text { containing } 16\end{array}$ & XM_001072487 & Txndc16 & $0.85(0.31)$ & 0.015 & 1.80 & $-0.72(0.32)$ & -1.65 & $0.51(0.32)$ & 1.42 \\
\hline
\end{tabular}

Values show gene expression. $\log _{2}$ ratio reaching at least \pm 0.85 and $p<0.05$ were considered as significant alterations

${ }^{\mathrm{a}} \mathrm{RGD}$ : rat genome database

${ }^{\mathrm{b}}$ non significant change $(p>0.05)$ 
Table 4 Genes significantly down-regulated in diabetes MVT-treated vs. diabetes vehicle-treated group on DNA microarray

\begin{tabular}{|c|c|c|c|c|c|c|c|c|c|c|}
\hline \multirow[b]{4}{*}{ Gene function } & \multirow[b]{4}{*}{ Gene Name provided by $R G D^{a}$} & \multirow[b]{4}{*}{ Acc. Number } & \multirow[b]{4}{*}{ Gene Symbol } & \multicolumn{3}{|c|}{ Diabetes MVT } & \multicolumn{2}{|c|}{ Diabetes Vehicle } & \multicolumn{2}{|l|}{ Control MVT } \\
\hline & & & & vs. & & & vs. & & vs. & \\
\hline & & & & \multicolumn{3}{|c|}{ Diabetes Vehicle } & \multicolumn{2}{|c|}{ Control Vehicle } & \multicolumn{2}{|c|}{ Control Vehicle } \\
\hline & & & & $\log _{2}(S D)$ & Corr. $p$ & Fold change & $\log _{2}(S D)$ & Fold Change & $\log _{2}(S D)$ & Fold Change \\
\hline Metabolism & dipeptidase 1 (renal) & L07315 & Dpep1 & $-1.02(0.27)$ & 0.007 & -2.03 & $0.79(0.47)$ & 1.72 & $-0.17(0.50)$ & -1.12 \\
\hline Metabolism & $\begin{array}{l}\text { glycosylphosphatidylinositol } \\
\text { anchored high density } \\
\text { lipoprotein binding protein } 1\end{array}$ & NM_001130547 & Gpihbp 1 & $-0.89(0.18)$ & 0.006 & -1.86 & $0.59(0.33)$ & 1.50 & $0.10(0.37)$ & 1.07 \\
\hline Metabolism & flavin containing monooxygenase 2 & NM_144737 & Fmo2 & $-0.85(0.36)$ & 0.028 & -1.80 & $0.80(0.24)$ & 1.74 & $0.12(0.29)$ & 1.08 \\
\hline Stress response & metallothionein 2a & NM_001137564 & Mt2a & $-1.70(0.66)$ & 0.018 & -3.24 & $1.61(0.34)$ & 3.06 & $0.24(0.53)$ & 1.18 \\
\hline Stress response & metallothionein 1a & NM_138826 & Mt1a & $-1.18(0.43)$ & 0.017 & -2.26 & $1.32(0.34)$ & 2.49 & $0.09(0.39)$ & 1.06 \\
\hline Immune response & FK506 binding protein 5 & NM_001012174 & Fkbp5 & $-1.09(0.32)$ & 0.008 & -2.13 & $1.13(0.52)$ & 2.19 & $0.83(0.74)$ & 1.77 \\
\hline Immune response & NLR family member X1 & NM_001025010 & Nirxl & $-1.07(0.43)$ & 0.023 & -2.10 & $0.87(0.48)$ & 1.83 & $0.30(0.43)$ & 1.23 \\
\hline Apoptosis/necrosis and inflammation & chemokine (C-X-C motif) ligand 13 & NM_001017496 & Cxcl13 & $-1.66(0.84)$ & 0.036 & -3.17 & $0.61(1.02)$ & 1.53 & $0.18(0.96)$ & 1.14 \\
\hline Apoptosis/necrosis and inflammation & interleukin 6 receptor & NM_017020 & $116 r$ & $-1.00(0.47)$ & 0.033 & -2.00 & $0.91(0.50)$ & 1.88 & $0.63(0.67)$ & 1.54 \\
\hline Cell growth and differentiation & brain expressed, $X$-linked 1 & NM_001037365 & Bex1 & $-1.97(0.45)$ & 0.004 & -3.92 & $1.41(0.30)$ & 2.65 & $0.25(0.81)$ & 1.19 \\
\hline Cell growth and differentiation & $\begin{array}{l}\text { wingless-type MMTV } \\
\text { integrationsite family, member } 2 B\end{array}$ & NM_001191848 & Wnt2b & $-1.66(0.48)$ & 0.007 & -3.15 & $1.32(0.11)$ & 2.50 & $0.16(0.11)$ & 1.11 \\
\hline Cell growth and differentiation & $\begin{array}{l}\text { RAB3 GTPase activating protein } \\
\text { subunit } 2\end{array}$ & Al072072 & Rab3gap2 & $-1.25(0.57)$ & 0.029 & -2.38 & $0.53(0.33)$ & 1.45 & $0.22(0.53)$ & 1.17 \\
\hline Cell growth and differentiation & $\mathrm{N}$-myc downstream regulated 1 & NM_001011991 & Ndrg1 & $-1.05(0.33)$ & 0.012 & -2.07 & $0.85(0.42)$ & 1.81 & $0.41(0.62)$ & 1.33 \\
\hline Cell growth and differentiation & $\begin{array}{l}\text { WNT1 inducible signaling pathway } \\
\text { protein } 2\end{array}$ & NM_031590 & Wisp2 & $-1.02(0.53)$ & 0.043 & -2.02 & $0.60(0.40)$ & 1.52 & $0.47(0.34)$ & 1.39 \\
\hline Cell growth and differentiation & $\begin{array}{l}\text { serine (or cysteine) peptidase } \\
\text { inhibitor, clade } \mathrm{A} \text {, member } 3 \mathrm{~N}\end{array}$ & NM_031531 & Serpina3n & $-0.90(0.48)$ & 0.048 & -1.87 & $-0.03(0.39)$ & -1.02 & $0.90(1.09)$ & 1.87 \\
\hline Receptors and ion channels & $\begin{array}{l}\text { ATPase, } \mathrm{H}^{+} \text {transporting,lysosomal } \\
\text { V1 subunit } \mathrm{G} 2\end{array}$ & NM_212490 & Atp6rig2 & $-1.05(0.43)$ & 0.024 & -2.06 & $0.92(0.41)$ & 1.89 & $-0.75(0.22)$ & -1.68 \\
\hline Receptors and ion channels & $\begin{array}{l}\text { melanocortin } 2 \text { receptoraccessory } \\
\text { protein }\end{array}$ & NM_001135834 & Mrap & $-0.92(0.42)$ & 0.033 & -1.89 & $0.65(0.19)$ & 1.56 & $0.12(0.21)$ & 1.09 \\
\hline $\begin{array}{l}\text { Signal transduction, regulation } \\
\text { of transcription }\end{array}$ & $\begin{array}{l}\text { cytochrome } \mathrm{P} 450 \text {, family } 26 \text {, } \\
\text { subfamily b, polypeptide } 1\end{array}$ & NM_181087 & Cyp26b1 & $-1.68(0.47)$ & 0.007 & -3.20 & $1.62(0.28)$ & 3.08 & $0.25(0.30)$ & 1.19 \\
\hline $\begin{array}{l}\text { Signal transduction, regulation } \\
\text { of transcription }\end{array}$ & $\begin{array}{l}\text { connector enhancer of kinase } \\
\text { suppressor of Ras } 1\end{array}$ & NM_001039011 & Cnksrl & $-1.64(0.38)$ & 0.004 & -3.13 & $1.31(0.67)$ & 2.48 & $0.39(0.72)$ & 1.31 \\
\hline Structural protein, cell adhesion & $\begin{array}{l}\text { solute carrier family } 43 \text { (amino acid } \\
\text { system } L \text { transporter), member } 2\end{array}$ & NM_001105812 & Slc43a2 & $-1.06(0.39)$ & 0.019 & -2.09 & $0.34(0.19)$ & 1.27 & $-0.07(0.18)$ & -1.05 \\
\hline Hormones & galanin/GMAP prepropeptide & NM_033237 & Gal & $-2.99(0.92)$ & 0.007 & -7.96 & $2.41(1.15)$ & 5.31 & $1.82(1.20)$ & 3.53 \\
\hline
\end{tabular}


Table 4 Genes significantly down-regulated in diabetes MVT-treated vs. diabetes vehicle-treated group on DNA microarray (Continued)

\begin{tabular}{|c|c|c|c|c|c|c|c|c|c|c|}
\hline Hormones & resistin & NM_144741 & Retn & $-1.03(0.44)$ & 0.025 & -2.05 & $1.08(0.60)$ & 2.12 & $0.51(0.96)$ & 1.43 \\
\hline Others & $\begin{array}{l}\text { similar to apolipoprotein L2; } \\
\text { apolipoprotein L-\|I }\end{array}$ & NM_001134801 & RGD1309808 & $-6.07(0.68)$ & $<0.001$ & -67.24 & $4.33(2.91)$ & 20.12 & $1.61(3.76)$ & 3.05 \\
\hline Others & secreted phosphoprotein 1 & NM_012881 & Spp1 & $-1.35(0.59)$ & 0.025 & -2.55 & $-0.40(0.77)$ & -1.32 & $2.30(1.49)$ & 4.93 \\
\hline Others & $\begin{array}{l}\text { elongation of very long chain fatty } \\
\text { acids protein 6-like }\end{array}$ & XM_003749393 & LOC100910695 & $-1.01(0.39)$ & 0.021 & -2.02 & $0.33(0.43)$ & 1.25 & $-0.94(0.55)$ & -1.92 \\
\hline Others & WW domain binding protein 5 & NM_001127502 & Wbp5 & $-0.99(0.20)$ & 0.005 & -1.99 & $0.54(0.15)$ & 1.45 & $0.07(0.38)$ & 1.05 \\
\hline Others & coiled-coil domain containing 136 & XM_001064000 & Ccdc136 & $-0.98(0.10)$ & 0.002 & -1.98 & $0.62(0.18)$ & 1.53 & $0.09(0.39)$ & 1.06 \\
\hline Others & multimerin 1 & XM_001071128 & Mmrn 1 & $-0.91(0.38)$ & 0.027 & -1.88 & $-0.31(0.36)$ & -1.24 & $-0.14(0.31)$ & -1.10 \\
\hline Others & epsin 3 & NM_001024791 & Epn3 & $-0.87(0.44)$ & 0.043 & -1.82 & $0.46(0.50)$ & 1.37 & $-0.16(0.32)$ & -1.12 \\
\hline
\end{tabular}

Values show gene expression. $\log _{2}$ ratio reaching at least \pm 0.85 and $p<0.05$ were considered as significant alterations

${ }^{a}$ RGD: rat genome database

bon significant change $(p>0.05)$ 
Table 5 Genes significantly up-regulated in diabetes MVT-treated vs. diabetes vehicle-treated group on DNA microarray

\begin{tabular}{|c|c|c|c|c|c|c|c|c|c|c|}
\hline \multirow[b]{4}{*}{ Gene function } & \multirow[b]{4}{*}{ Gene Name provided by $R G D^{a}$} & \multirow[b]{4}{*}{ Acc. Number } & \multirow[b]{4}{*}{ Gene Symbol } & \multirow{3}{*}{\multicolumn{3}{|c|}{$\begin{array}{l}\text { Diabetes MVT } \\
\text { vs. } \\
\text { Diabetes Vehicle }\end{array}$}} & \multirow{3}{*}{\multicolumn{2}{|c|}{$\begin{array}{l}\text { Diabetes Vehicle } \\
\text { vs. } \\
\text { Control Vehicle }\end{array}$}} & \multirow{3}{*}{\multicolumn{2}{|c|}{$\begin{array}{l}\text { Control MVT } \\
\text { vs. } \\
\text { Control Vehicle }\end{array}$}} \\
\hline & & & & & & & & & & \\
\hline & & & & & & & & & & \\
\hline & & & & $\log _{2}(\mathrm{SD})$ & Corr. $p$ & Fold change & $\log _{2}(\mathrm{SD})$ & Fold Change & $\log _{2}(\mathrm{SD})$ & Fold Change \\
\hline Metabolism & $\begin{array}{l}\text { L-2-hydroxyglutarate } \\
\text { dehydrogenase }\end{array}$ & NM_001108028 & L2hgdh & $1.06(0.49)$ & 0.032 & 2.09 & $-0.52(1.01)$ & -1.44 & $0.04(0.92)$ & 1.03 \\
\hline $\begin{array}{l}\text { Apoptosis/necrosis and } \\
\text { inflammation }\end{array}$ & $\begin{array}{l}\text { chemokine (C-X-C motif) } \\
\text { ligand } 9\end{array}$ & NM_145672 & $C \times C 19$ & $1.03(0.40)$ & 0.021 & 2.04 & $-0.29(0.60)$ & -1.22 & $-0.19(0.81)$ & -1.14 \\
\hline $\begin{array}{l}\text { Apoptosis/necrosis and } \\
\text { inflammation }\end{array}$ & $\begin{array}{l}\text { caspase recruitment } \\
\text { domain family, member } 9\end{array}$ & NM_022303 & Card9 & $1.82(0.52)$ & 0.007 & 3.53 & $-2.74(0.64)$ & -6.69 & $-1.20^{b}(0.88)$ & -2.29 \\
\hline $\begin{array}{l}\text { Receptors and ion } \\
\text { channels }\end{array}$ & adrenoceptor alpha 1D & NM_024483 & Adrald & $1.12(0.40)$ & 0.017 & 2.17 & $-1.21(0.52)$ & -2.31 & $-1.03^{b}(1.36)$ & -2.04 \\
\hline $\begin{array}{l}\text { Receptors and ion } \\
\text { chanells }\end{array}$ & $\begin{array}{l}\text { FXYD domain-containing } \\
\text { ion transport regulator } 3\end{array}$ & NM_172317 & Fxyd3 & $1.97(0.48)$ & 0.004 & 3.92 & $-1.01(0.49)$ & -2.01 & $-0.36(0.85)$ & -1.29 \\
\hline $\begin{array}{l}\text { Signal transduction, regulation } \\
\text { of transcription }\end{array}$ & $\begin{array}{l}\text { regulator of telomere } \\
\text { elongation helicase } 1\end{array}$ & NM_001191857 & Rtel1 & $1.14(0.27)$ & 0.006 & 2.20 & $-0.71(1.02)$ & -1.64 & $0.58(1.14)$ & 1.49 \\
\hline $\begin{array}{l}\text { Signal transduction, } \\
\text { regulation of transcription }\end{array}$ & $\begin{array}{l}\text { staufen double-stranded } \\
\text { RNA binding protein } 2\end{array}$ & NM_001007149 & Stau2 & $1.36(0.71)$ & 0.042 & 2.56 & $-0.38(0.27)$ & -1.30 & $0.22(0.41)$ & 1.16 \\
\hline $\begin{array}{l}\text { Structural protein, cell } \\
\text { adhesion }\end{array}$ & protocadherin 17 & NM_001107279 & Pcdh17 & $0.90(0.43)$ & 0.036 & 1.86 & $-0.94(0.44)$ & -1.91 & $-0.65(0.43)$ & -1.57 \\
\hline Hormones & inhibin alpha & NM_012590 & Inha & $1.59(0.79)$ & 0.035 & 3.01 & $-0.89(0.39)$ & -1.85 & $0.66(0.21)$ & 1.58 \\
\hline Others & $\begin{array}{l}\text { similar to HTGN29 protein; } \\
\text { keratinocytes associated } \\
\text { transmembrane protein } 2\end{array}$ & NM_001106999 & RGD131352 & $1.05(0.48)$ & 0.032 & 2.07 & $0.29(0.49)$ & 1.23 & $0.49(0.53)$ & 1.41 \\
\hline Others & WDNM1 homolog & NM_001003706 & LOC360228 & $1.32(0.63)$ & 0.033 & 2.50 & $-0.59(0.77)$ & -1.50 & $1.01^{b}(0.67)$ & 2.01 \\
\hline Others & ring finger protein 135 & NM_001012010 & Rnf135 & $0.86(0.33)$ & 0.023 & 1.82 & $-0.44(0.08)$ & -1.35 & $-0.06(0.46)$ & -1.05 \\
\hline Others & uncharacterized LOC100910110 & XR_146304 & LOC100910110 & $2.32(0.31)$ & 0.001 & 5.01 & $-1.94(0.32)$ & -3.85 & $-0.46(1.57)$ & -1.38 \\
\hline Others & uncharacterized LOC100909684 & XR_146107 & LOC10099684 & $2.55(1.40)$ & 0.045 & 5.85 & $-3.07(1.43)$ & -8.43 & $-0.42(0.76)$ & -1.34 \\
\hline Others & serine hydrolase-like 2 & NM_001130579 & $\operatorname{serh} 12$ & $5.17(0.48)$ & $<0.001$ & 35.96 & $-3.62^{b}(2.81)$ & -12.31 & $-3.45^{b}(2.82)$ & -10.92 \\
\hline
\end{tabular}

Values show gene expression. $\log _{2}$ ratio reaching at least \pm 0.85 and $p<0.05$ were considered as significant alterations

aRGD: rat genome database

${ }^{b}$ non significant change $(p>0.05)$ 

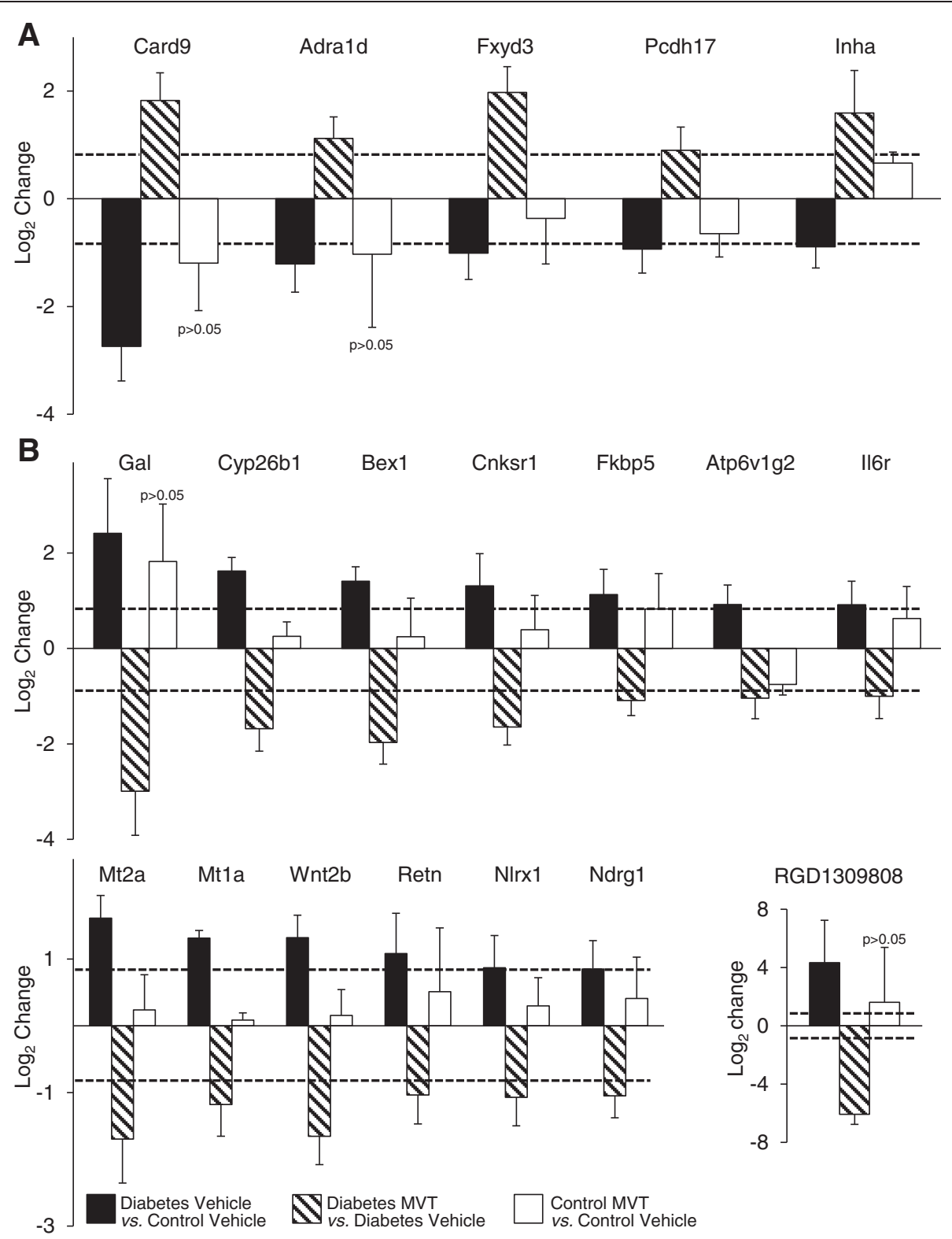

Fig. 2 Genes with significantly and oppositely altered expression in diabetes vehicle-treated vs. diabetes MVT-treated group. a Significantly down-regulated genes in diabetes vehicle-treated group vs. control vehicle-treated group which are up-regulated in diabetes MVT-treated group vs. diabetes vehicle treated-group. No significant change in control MVT-treated group vs. control vehicle-treated group. $\mathbf{b}$ Significantly up-regulated genes in diabetes vehicle-treated group vs. control vehicle-treated group which are down-regulated in diabetes MVT-treated group vs. diabetes vehicle-treated group. No significant change in control MVT-treated group vs. control vehicle-treated group. Values are expressed as mean \pm S.E.M. Log 2 ratio reaching at least \pm 0.85 (represented with dotted lines) and $p<0.05$ were considered as significant alterations

insulin levels in male diabetic rats [14]. We have shown here that the development of DM induces marked alterations in the cardiac gene expression pattern. This is the first demonstration that a MVT preparation significantly altered the myocardial [38, 39] gene expression pattern by altering transcript levels of several genes in both diabetic and healthy rats. The significantly altered genes can be classified into different clusters (e.g. metabolism; stress response; immune response; cell growth and differentiation; ion channels and receptors; signal transduction and regulation of transcription; structural proteins and cell adhesion; hormones; transport; etc.). Some of these genes are related to the development of diabetic cardiomyopathy (e.g. cardiac hypertrophy and fibrosis, stress response, hormones associated with insulin resistance, etc.). Moreover, some other genes without any definite function in the myocardium were also changed in response to DM or MVT-treatment. 
Table 6 Genes significantly down-regulated in control MVT-treated vs. control vehicle-treated group on DNA microarray

\begin{tabular}{|c|c|c|c|c|c|c|c|c|c|c|}
\hline \multirow[b]{4}{*}{ Gene function } & \multirow[b]{4}{*}{ Gene Name provided by $R G D^{a}$} & \multirow[b]{4}{*}{ Acc. Number } & \multirow[b]{4}{*}{ Gene Symbol } & \multirow{3}{*}{\multicolumn{3}{|c|}{$\begin{array}{l}\text { Control MVT } \\
\text { vs. } \\
\text { Control Vehicle }\end{array}$}} & \multirow{3}{*}{\multicolumn{2}{|c|}{$\begin{array}{l}\text { Diabetes Vehicle } \\
\text { vs. } \\
\text { Control Vehicle }\end{array}$}} & \multirow{3}{*}{\multicolumn{2}{|c|}{$\begin{array}{l}\text { Diabetes MVT } \\
\text { vs. } \\
\text { Diabetes Vehicle }\end{array}$}} \\
\hline & & & & & & & & & & \\
\hline & & & & & & & & & & \\
\hline & & & & $\log _{2}(\mathrm{SD})$ & Corr. $p$ & Fold change & $\log _{2}(\mathrm{SD})$ & Fold Change & $\log _{2}(S D)$ & Fold Change \\
\hline Stress response & $\begin{array}{l}\text { APEX (apurinic/apyrimidinic) } \\
\text { endonuclease) } 2\end{array}$ & NM_001079892 & Apex2 & $-1.18(0.63)$ & 0.043 & -2.26 & $-0.94(0.56)$ & -1.92 & $0.09(0.26)$ & 1.06 \\
\hline Receptors and ion channels & sodium leak channel, non-selective & NM_153630 & Nalcn & $-0.85(0.44)$ & 0.043 & -1.80 & $-0.59(0.36)$ & -1.50 & $0.16(0.41)$ & 1.12 \\
\hline $\begin{array}{l}\text { Signal transduction, } \\
\text { regulation of transcription }\end{array}$ & $\begin{array}{l}\text { triggering receptor expressed on } \\
\text { myeloid cells } 2\end{array}$ & NM_001106884 & Trem2 & $-1.03(0.40)$ & 0.021 & -2.05 & $-0.21(0.88)$ & -1.15 & $-0.98(0.94)$ & -1.98 \\
\hline Transport & $\begin{array}{l}\text { hemoglobin, beta adult } \\
\text { major chain }\end{array}$ & NM_198776 & $H b b-b 1$ & $-2.23(0.76)$ & 0.016 & -4.71 & $-1.94(0.75)$ & -3.83 & $-0.40(0.77)$ & -1.32 \\
\hline Transport & globin, alpha & NM_001013853 & LOC287167 & $-1.80(0.76)$ & 0.020 & -3.47 & $-1.64(0.72)$ & -3.12 & $-0.23(0.81)$ & -1.18 \\
\hline Others & $\begin{array}{l}\text { EF-hand calcium binding } \\
\text { domain } 6\end{array}$ & XM_001077962 & Efcab6 & $-1.66(0.62)$ & 0.017 & -3.15 & $0.40(0.99)$ & 1.32 & $-1.36^{b}(1.38)$ & -2.57 \\
\hline
\end{tabular}

Values show gene expression. $\log _{2}$ ratio reaching at least \pm 0.85 and $p<0.05$ were considered as significant alterations

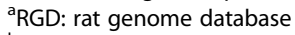

${ }^{b}$ non significant change $(p>0.05)$ 
Table 7 Genes significantly up-regulated in control MVT-treated vs. control vehicle-treated group on DNA microarray

\begin{tabular}{|c|c|c|c|c|c|c|c|c|c|c|}
\hline \multirow[b]{4}{*}{ Gene function } & \multirow[b]{4}{*}{ Gene Name provided by $R G D^{a}$} & \multirow[b]{4}{*}{ Acc. Number } & \multirow[b]{4}{*}{ Gene Symbol } & \multirow{3}{*}{\multicolumn{3}{|c|}{$\begin{array}{l}\text { Control MVT } \\
\text { vs. } \\
\text { Control Vehicle }\end{array}$}} & \multirow{3}{*}{\multicolumn{2}{|c|}{$\begin{array}{l}\text { Diabetes Vehicle } \\
\text { vs. } \\
\text { Control Vehicle }\end{array}$}} & \multirow{3}{*}{\multicolumn{2}{|c|}{$\begin{array}{l}\text { Diabetes MVT } \\
\text { vs. } \\
\text { Diabetes Vehicle }\end{array}$}} \\
\hline & & & & & & & & & & \\
\hline & & & & & & & & & & \\
\hline & & & & $\log _{2}(S D)$ & Corr. $p$ & Fold change & $\overline{\log _{2}(S D)}$ & $\begin{array}{c}\text { Fold Change } \\
\text {. }\end{array}$ & $\log _{2}(S D)$ & $\overline{\text { Fold Change }}$ \\
\hline Metabolism & proline dehydrogenase (oxidase) 1 & NM_001135778 & Prodh & $0.93(0.50)$ & 0.043 & 1.91 & $0.95(0.48)$ & 1.93 & $-0.27(0.63)$ & -1.21 \\
\hline Metabolism & enolase 2, gamma, neuronal & NM_139325 & Eno2 & $1.00(0.30)$ & 0.017 & 2.00 & $0.98^{b}(0.85)$ & 1.97 & $-1.32^{b}(1.12)$ & -2.50 \\
\hline Metabolism & 4-hydroxyphenylpyruvate dioxygenase & NM_017233 & Hpd & $1.00(0.48)$ & 0.034 & 2.01 & $1.07(0.38)$ & 2.09 & $-0.06(0.34)$ & -1.04 \\
\hline Immune response & complement factor B & NM_212466 & $C f b$ & $0.85(0.32)$ & 0.025 & 1.80 & $0.14(0.34)$ & 1.10 & $0.22(0.34)$ & 1.17 \\
\hline Immune response & $2^{\prime}-5^{\prime}$ oligoadenylate synthetase $1 \mathrm{~A}$ & NM_138913 & Oasia & $0.92(0.33)$ & 0.020 & 1.90 & $0.40(0.28)$ & 1.32 & $-0.43(0.24)$ & -1.35 \\
\hline Immune response & 2-5 oligoadenylate synthetase 1B & AF068268 & Oasib & $1.04(0.18)$ & 0.015 & 2.06 & $-0.52(0.50)$ & -1.44 & $0.11(0.83)$ & 1.08 \\
\hline Immune response & 2'-5' oligoadenylate synthetase 11 & NM_001009680 & Oas1i & $0.87(0.24)$ & 0.018 & 1.83 & $0.13(0.31)$ & 1.09 & $-0.29(0.22)$ & -1.22 \\
\hline Immune response & interferon regulatory factor 7 & NM_001033691 & Irf7 & $1.13(0.27)$ & 0.016 & 2.18 & $-0.05(0.12)$ & -1.04 & $0.25(0.20)$ & 1.19 \\
\hline Immune response & $\begin{array}{l}\text { complement component } 4 \mathrm{~A} \\
\text { (Rodgers blood group) }\end{array}$ & NM_031504 & $\mathrm{C} 4 a$ & $1.18(0.39)$ & 0.017 & 2.27 & $0.29(0.44)$ & 2.27 & $0.05(0.34)$ & 1.04 \\
\hline Immune response & hepcidin antimicrobial peptide & NM_053469 & Hamp & $1.38(0.74)$ & 0.040 & 2.60 & $0.59(0.77)$ & 1.51 & $-0.56(0.74)$ & -1.47 \\
\hline Immune response & myxovirus (influenza virus) resistance 2 & NM_134350 & $M \times 2$ & $2.14(0.95)$ & 0.020 & 4.41 & $0.42(0.63)$ & 1.34 & $-0.72(0.67)$ & -1.65 \\
\hline Cell growth and differentiation & neuronatin & NM_053601 & Nnat & $0.99(0.41)$ & 0.025 & 1.98 & $0.73(0.40)$ & 1.66 & $-0.06(0.74)$ & -1.04 \\
\hline Cell growth and differentiation & $\begin{array}{l}\mathrm{H} 19 \text {, imprinted maternally expressed } \\
\text { transcript }\end{array}$ & NR_027324 & H19 & $1.16(0.44)$ & 0.020 & 2.24 & $0.92(0.49)$ & 1.89 & $-0.53(0.47)$ & -1.44 \\
\hline Receptors and ion channels & $\begin{array}{l}\text { ATPase, } \mathrm{H}^{+} / \mathrm{K}^{+} \text {exchanging, alpha } \\
\text { polypeptide }\end{array}$ & NM_012509 & Atp $4 a$ & $0.86(0.19)$ & 0.017 & 1.81 & $0.45(0.48)$ & 1.37 & $-0.05(0.59)$ & -1.04 \\
\hline Receptors and ion channels & sarcolipin & NM_001013247 & $\sin$ & $1.09(0.61)$ & 0.043 & 2.13 & $1.07(0.61)$ & 2.10 & $-0.23(0.42)$ & -1.17 \\
\hline Receptors and ion channels & $\begin{array}{l}\text { ATPase, } \mathrm{Na}^{+} / \mathrm{K}^{+} \text {transporting, beta } 4 \\
\text { polypeptide }\end{array}$ & NM_053381 & Atp164 & $1.14(0.63)$ & 0.043 & 2.21 & $0.41(0.64)$ & 1.33 & $0.04(0.81)$ & 1.03 \\
\hline Others & $2^{\prime}-5^{\prime}$ oligoadenylate synthetase-like 2 & NM_001009682 & Oas12 & $0.96(0.34)$ & 0.020 & 1.95 & $-0.21(0.19)$ & -1.15 & $0.08(0.14)$ & 1.05 \\
\hline Others & GRAM domain containing 3 & NM 001014011 & Gramd3 & $0.97(0.31)$ & 0.018 & 1.96 & $-0.03(0.41)$ & -1.02 & $0.36(0.79)$ & 1.29 \\
\hline
\end{tabular}

Values show gene expression. $\log _{2}$ ratio reaching at least \pm 0.85 and $p<0.05$ were considered as significant alterations

${ }^{a}$ RGD: rat genome database

${ }^{b}$ non significant change $(p>0.05)$ 
Table 8 Primers to qRT-PCR

\begin{tabular}{|c|c|c|c|c|c|c|}
\hline Gene name & Gene symbol & Acc. Number & Forward & Length & Reverse & Length \\
\hline metallothionein 1a & Mt1a & NM_138826 & caccagatctcggaatggac & 20 & aggagcagcagctcttcttg & 20 \\
\hline metallothionein $2 a$ & Mt2a & NM_001137564 & catggaccccaactgctc & 18 & aggtgcatttgcattgtttg & 20 \\
\hline $\begin{array}{l}\text { cytochrome } \mathrm{P} 450 \text {, family } 26 \text {, } \\
\text { subfamily b, polypeptide } 1\end{array}$ & Cyp26b1 & NM_181087 & acggcaaggagatgacca & 18 & gcataggctgcgaagatca & 19 \\
\hline galanin prepropeptide & Gal & NM_033237 & tggagtttctcagtttcttgcac & 23 & ggtgtggtctcaggactgct & 20 \\
\hline $\begin{array}{l}\text { connector enhancer of kinase } \\
\text { suppressor of Ras } 1\end{array}$ & Cnksr1 & NM_001039011 & tgtggctgggatctgtcac & 19 & tgctggtggtgtgaatttct & 20 \\
\hline
\end{tabular}

\section{Genes associated with diabetic cardiomyopathy}

One of the major cardiovascular complications of DM is diabetic cardiomyopathy (DCM) $[40,41]$, which is defined as left ventricular dysfunction with hypertrophy and fibrosis in the absence of hypertension, coronary artery disease and valvular or congenital heart disease [42]. The complex underlying molecular mechanisms of the above-mentioned functional and morphologic changes have been intensively investigated [40-42]. In our present study, we have shown altered expression of several genes related to cardiac hypertrophy and remodelling in accordance with the literature (e.g. down-regulation of caspase recruitment domain family, member 9 (Card9) [43] and adrenoceptor alpha 1d (adra1d) [44]; up-regulation of the angiogenesis inductor cytochrome P450, family 26, subfamily B, polypeptide 1 (Cyp26b1) [45, 46]; FXYD domain containing ion transport regulator 3 (Fxyd3) also called phospholemman-like protein potentially regulating
$\mathrm{Na}^{+} / \mathrm{K}^{+} /$ATP-ase activity [47-49]; ATPase, $H^{+}$Transporting, Lysosomal $13 \mathrm{kDa}, \mathrm{V1}$ Subunit G21 (Atp6v1g2) [50] related to hepatitis $C$ virus-associated dilated cardiomyopathy; and a well-known marker of hypertrophy and heart failure, natriuretic peptide $A$ (Nppa) [40, 41] (Tables 2 and 3). In our present study, another group of genes altered in response to DM is involved in cell proliferation in different organs (e.g. down-regulation of the antiproliferative and tumour suppressor protocadherin-17 (Pcdh17) [51] and up-regulation of the insulin signalling pathway promoter connector enhancer of kinase suppressor of Ras 1 (Cnksr1) [52, 53]; and wingless-type MMTV integration site family, member $2 B$ (Wnt2b) playing a role in pancreatic beta cell replication [54] (Tables 2 and 3). These aforementioned studies, in agreement with our present study, suggest that altered metabolic parameters in DM may induce cardiac gene expression changes leading to the induction of general mechanisms of cell proliferation and

Table 9 qRT-PCR results

\begin{tabular}{|c|c|c|c|c|c|c|c|c|}
\hline \multirow{3}{*}{ Description } & \multirow{3}{*}{ Gene symbol } & \multirow{3}{*}{ Acc. Number } & \multicolumn{6}{|c|}{ Diabetes Vehicle vs. Control Vehicle } \\
\hline & & & \multicolumn{2}{|c|}{$\underline{\text { DNA MICROARRAY }}$} & \multicolumn{3}{|l|}{ qRT-PCR } & \multirow[t]{2}{*}{ confirmed } \\
\hline & & & fold change & $p$ value & $\log _{2}$ ratio $(S D)$ & fold change & regulation & \\
\hline metallothionein 1a & Mt1a & NM_138826 & 2.49 & 0.005 & $2.36(1.35)$ & 5.13 & up & yes \\
\hline metallothionein 2a & $\mathrm{Mt} 2 \mathrm{a}$ & NM_001137564 & 3.06 & 0.003 & $2.36(0.93)$ & 5.12 & up & yes \\
\hline $\begin{array}{l}\text { cytochrome P450, family } 26 \text {, } \\
\text { subfamily b, polypeptide } 1\end{array}$ & Cyp26b2 & NM_181087 & 3.08 & 0.003 & $2.50(0.85)$ & 5.65 & up & yes \\
\hline galanin/GMAP prepropeptide & Gal & NM_033237 & 5.31 & 0.018 & $2.69(0.86)$ & 6.43 & up & yes \\
\hline \multirow[t]{2}{*}{$\begin{array}{l}\text { connector enhancer of kinase } \\
\text { suppressor of Ras } 1\end{array}$} & Cnksr2 & NM_001039011 & 2.48 & 0.025 & $0.002(0.26)$ & 1.00 & no change & no \\
\hline & & & \multicolumn{6}{|c|}{ Diabetes MVT vs. Diabetes Vehicle } \\
\hline \multirow[t]{2}{*}{ Description } & Gene symbol & Acc. Number & \multicolumn{2}{|c|}{ DNA MICROARRAY } & \multicolumn{3}{|l|}{ qRT-PCR } & confirmed \\
\hline & & & fold change & $p$ value & $\log _{2}$ ratio $(S D)$ & fold change & regulation & \\
\hline metallothionein 1a & Mt1a & NM_138826 & -2.26 & 0.017 & $-1,44(0.91)$ & -2.71 & down & yes \\
\hline metallothionein 2a & Mt2a & NM_001137564 & -3.24 & 0.018 & $-2.53(0.68)$ & -5.76 & down & yes \\
\hline $\begin{array}{l}\text { cytochrome P450, family } 26 \text {, } \\
\text { subfamily b, polypeptide } 1\end{array}$ & Cyp26b2 & NM_181087 & -3.20 & 0.007 & $-2.91(0.32)$ & -7.50 & down & yes \\
\hline galanin/GMAP prepropeptide & Gal & NM_033237 & -7.96 & 0.007 & $-2.72(0.64)$ & -6.60 & down & yes \\
\hline $\begin{array}{l}\text { connector enhancer of kinase } \\
\text { suppressor of Ras } 1\end{array}$ & Cnksr2 & NM_001039011 & -3.13 & 0.004 & $-0.11(0.33)$ & 1.08 & no change & no \\
\hline
\end{tabular}


cardiac hypertrophy. Nevertheless, these aforementioned genes have not previously been shown to play a role in the development of diabetic cardiomyopathy. In our present study, MVT-treatment in diabetic rats resulted in opposite gene expression changes in case of some aforementioned genes (e.g. caspase recruitment domain family, member 9 (Card9); adrenoceptor alpha 1d (adra1d); cytochrome P450, family 26, subfamily B, polypeptide 1 (Cyp26b1; FXYD domain containing ion transport regulator 3 (Fxyd3); ATPase, $H^{+}$Transporting, Lysosomal $13 \mathrm{kDa}, \mathrm{V1}$ Subunit G21 (Atp6v1g2); etc.) showing a beneficial effect of MVT-treatment on the development of diabetic cardiomyopathy (Tables 2 and 5, Fig. 2). Although we have not characterized diabetic cardiomyopathy in our present study, STZ-treated rats are well known to develop this cardiovascular complication at ages similar to that of used in the present study [19].

\section{Genes associated with increased oxidative/nitrative stress in DM}

Increased cardiovascular oxidative and nitrative stress is another well-known factor in the development of diabetic cardiomyopathy [40, 41]. In the present study, members of another functional gene cluster related to oxidative/nitrative stress and stress response showed altered expression in diabetic vehicle-treated hearts as compared to controls, in accordance with literature data (e.g. up-regulation of the zinc ion containing antioxidative metallothionein $1 a(M t 1 a)$ and metallothionein $2 a$ $(M t 2 a)$ [55, 56]; the cardiovascular risk factor interleukin-6 receptor (Ilr6) [57, 58]; the antioxidative heme oxygenase (decycling) 1 (Hmox1) [59]; and glutathione Stransferase, theta 3 (Gstt3) [60]) (Tables 2 and 3). Glutathione S-transferase catalyzes the conjugation of reduced glutathione on a wide variety of substrates [60] including reactive oxygen and nitrogen species [61]. Interestingly, we have found here the overexpression of glutathione $S$ transferase in DM similar to the up-regulation of this gene in metabolic syndrome [23] and cholesterol dietinduced hyperlipidaemia [62] in our previous studies. Our results suggest that up-regulation of antioxidative genes including glutathione S-transferase; heme oxygenase 1; metallothionein $1 a$ and $2 a$ may be an adaptive response in DM to antagonize elevated oxidative/nitrative stress in the myocardium. In contrast, decreased expression of metallothionein proteins have been reported in the heart [63] and the aorta [64] in experimental diabetes. Moreover, it has been published that the expression of metallothioneins could be increased by a chelatorregulated restoration of copper regulation [63] and zinc supplementation in experimental diabetes [64, 65]. Nevertheless, it should be noted that these aforementioned studies used different types of diabetes models (a genetic T1DM model OVE26 mice and single injection of STZ in adult mice or rats) with more severe hyperglycaemia than that developed in our model in the present study. In addition, we have previously shown marked differences in gene expression profiles in vascular and cardiac tissues in response to nitrate tolerance, which indicates different tissue-specific signalling pathways in different organs [66]. MVT-treatment in diabetic rats showed opposite gene expression changes in the cases of the aforementioned genes (Tables 2 and 5, Fig. 2). This could be explained by the beneficial effect of MVT-treatment on the severity of DM and potentially reduced oxidative/nitrative stress.

\section{Genes associated with insulin resistance}

Insulin resistance is another well-known phenomenon in diabetic cardiomyopathy [40,41]. Although the precise mechanisms by which cardiac insulin resistance developed in DM are poorly characterized, numerous metabolic and hormonal changes in the diabetic heart have been demonstrated [19-22, 40, 41]. In this present study, we have shown altered expression of several genes related to insulin resistance in the hearts of diabetic rats (e.g. upregulation of resistin (Retn) responsible for induction of cardiac insulin resistance in rodents and chronic inflammation in humans [67] and FK506 binding protein 5 (Fkbp5) associated with decreased ligand sensitivity of the glucocorticoid receptor [68]. Interestingly, here we have shown up-regulation of galanin/GMAP prepropeptide (Gal) which has trophic effects on cells and increases insulin sensitivity in the diabetic heart [69]. Increased expression of galanin might be a counter-regulatory mechanism against insulin resistance in the diabetic heart. Surprisingly, a regulatory hormone of the reproductive function, inhibin 1-alpha (Inha) [70] showed significant upregulation in the present study. Association of this gene with heart or DM has never been shown previously.

\section{Genes not associated with DM before}

Some of the genes showing altered expression in diabetic hearts in the present study have not yet been related to diabetic cardiomyopathy (e.g. up-regulation of prostaglandin b2 synthase (brain) (Ptgds); fibroblast growth factor (Fgf18) and down-regulation of HOP homeobox (Hopx); neuronal regeneration related protein (Nrep); etc.). Interestingly, we have found here the overexpression of brain expressed X-linked 1 (Bex1) in DM similar to the upregulation of this gene in metabolic syndrome [23] in our previous study. Some other altered genes were not classified into specific functional clusters or indicated as yet uncharacterized, predicted genes and fragments (e.g. upregulation of RGD1309808 also called similar to apolipoprotein L2 or down-regulation of uncharacterized LOC100909684 and LOC100910110 genes), the relevance of which should not be ignored. 
Genes altered in healthy condition due to MVT-treatment Regular consumption of MVT preparations as medical food for diabetics is common in developed countries. However, preclinical or clinical evaluation of such preparations is surprisingly limited in the literature [12-16]. To the best of our knowledge, none of the investigated and significantly altered genes in this study has been reported to show altered expression, either in healthy or in diabetic hearts in response to MVT-treatment. In the present study, 24 genes showed significant alteration in control MVT-treated hearts as compared to control vehicle-treated hearts (Tables 5 and 6), however, we did not observe any phenotypic changes in this group. Out of the 24 aforementioned genes, 18 were not significantly altered in diabetic MVT-treated rats compared to the diabetes vehicle-treated ones; therefore, these genes might be associated to the beneficial effects of MVTtreatment observed in the diabetic group. Accordingly, a major cluster of significantly altered cardiac genes in response to MVT treatment in control animals was associated with immune and antimicrobial response (e.g. complement factor B (Cfb); complement component $4 a$ (C4a); interferon regulatory factor 7 (irf7); hepcidin antimicrobial peptide (Hamp); myxovirus (influenza virus) resistance $2(M \times 2)$; and viral RNA degradation regulators including 2'-5" oligoadenylate synthetase $1 A ; 1 B$; and $1 \mathrm{~L}$; as well as $2^{\prime}-5^{\prime}$ oligoadenylate synthetase-like 2) which is in line with the known immune system boosting effect of some of the components of the MVT preparation such as e.g. selenium [71].

\section{Limitations}

Our study is not without limitations. Based on our present results one may not be able to differentiate entirely between the effects of diabetes and postnatal development due to insulin insufficiency, however, this model may also have clinical significance in DM in the pediatric age [72]. Furthermore, cardiac morphological and functional parameters to verify the development of diabetic cardiomyopathy were not investigated in this study; however, the neonatal STZ-injected rat is a wellcharacterized model of diabetes with cardiovascular complications including hypertension and LV hypertrophy with decreased cardiac function at a similar age to that used in our present study [28-34]. Although our study does not specify which cell type (i.e. cardiomyocyte, fibroblast, smooth muscle cell, etc.) may be responsible for the observed alterations of cardiac gene expression due to DM, the contribution of cardiomyocytes is likely the most significant $[38,39]$. Although longer ex vivo heart perfusion was reported to alter cardiac gene expression profile [73], it is unlikely that 10 min perfusion in our present study significantly affected gene expression profile, however, it still cannot be completely excluded that the stability of transcripts might have been influenced differentially by the crystalloid buffer used during ex vivo heart perfusion.

Our results regarding altered cardiac gene expression due to DM are based on determinations of 41012 cardiac transcript levels. Examination of the role of corresponding proteins was out of the scope of the present study; however, mechanistic data would strengthen our results. In addition, it is unclear whether significantly altered gene expression changes are causes or consequences in the development of diabetic cardiomyopathy. Moreover, it also needs to be further investigated whether the MVT-treatment in DM associated with opposite cardiac gene expression changes is the cause of attenuation of the severity of DM or a consequence of DM. Therefore, focused future studies are necessary to perform in-depth functional assessment of selected genes and specifically aim to investigate the precise role of these genes in the cardiac effects of diabetes mellitus and/or MVTtreatment. The results of the present study do not provide evidence on the mechanism of the MVT preparation and the different contributions of the 26 individual components. We assume that the potential interactions of these components and their combined effects rather than the value of a single component could be responsible for the effects of the MVT preparation on cardiac gene expression changes and the severity of DM; however, the effects of each component on gene expression or DM were not investigated in the present study. Indeed, a recent report [74] showing a reduction of cancer risk in humans by a daily intake of multivitamins and minerals suggests that the combined effect of multivitamins is more important in the beneficial effect than any single component.

\section{Conclusions}

In summary, we have found that 12 week-old STZtreated rats developed DM characterized by hyperglycaemia and impaired glucose tolerance. We have shown that the severity of DM could be attenuated by a complex MVT preparation. We have demonstrated for the first time that MVT-treatment is associated with profound modifications of the cardiac transcriptome in both healthy and diabetic conditions. In addition, several of the genes showing altered expression in the hearts of diabetic rats have not been implicated in DM previously. We conclude that DM alters the gene expression pattern of the myocardium, which may be involved in the development of cardiac pathologies in the state of DM and these pathological processes may be attenuated by MVT-treatment. Based on our exploratory results, future preclinical and clinical studies should be carried out to investigate the precise role of specific genes in the development of cardiac consequences of DM and MVTtreatment to obtain deeper mechanistic insight. 


\section{Additional file}

\section{Additional file 1: Ingredients of the standard rat chow.}

\section{Competing interests}

Béres Pharmaceuticals Ltd., Pharmahungary Group and University of Szeged had a consortial grant funded by the National Development Agency (MED_FOOD TECH_08-A1-2008-0275) to develop MVT preparations for diabetic patients; Béres Pharmaceuticals Ltd. was the leader of this consortial project. C.S., J. B. and C. K. are employed by Béres Pharmaceuticals Ltd. P.F. is the owner and T.C. and C.C. were involved in the management of Pharmahungary Group, a pharmaceutical/biotechnological company. The authors declare that they have no competing interests.

\section{Authors' contributions}

$C K, P F$, and TC conception and design of research; MS, GS, AZ, KE, VF, CS, CC, $\mathrm{JB}$, and TC performed experiments; MS, GS, MP, AZ, KE, VF, CS, CC, JB, and TC analysed data; MS, GS, MP, AZ, KE, VF, CS, CC, JB, and TC interpreted results of experiments; MS and MP prepared figures and tables; MS, AZ and TC drafted manuscript; MS, MP, AZ, PF, and TC edited and revised manuscript; MS, GS, MP, AZ, KÉ, VF, CS, JB, CC, CK, PF, and TC approved final version of manuscript. All authors read and approved the final manuscript.

\section{Acknowledgement}

We acknowledge the excellent technical support of Szilvia Török for blood sampling and biochemical assays and Jeremy Parrott PhD language editor for proofreading the manuscript.

\section{Grants}

MED_FOOD TECH_08-A1-2008-0275, Baross DA-TECH-07-2008-0041, TÁMOP4.2.1/B-09/1/KONV-2010-0005, TÁMOP-4.2.2/B-10/1-2010-0012, TÁMOP-4.2.2.A11/1/KONV-20 2012-0035), the Hungarian Scientific Research Fund (OTKA K79167), European Regional Development Fund and VÁTI Hungarian Nonprofit LLC for Regional Development and Town Planning (HURO/0901/137/ 2.2.2-HU-RO-TRANS-MED). M. Sárközy held a "Jedlik Ányos Predoctoral Fellowship". This research was realized in the frames of TÁMOP-4.2.4.A/211/1-2012-0001 National Excellence Program. CC was supported by the János Bolyai Research Scholarship of the Hungarian Academy of Sciences.

\section{Author details}

${ }^{1}$ Department of Biochemistry, Faculty of Medicine, University of Szeged, Szeged, Hungary. ${ }^{2}$ Institute of Genetics, Biological Research Center of the Hungarian Academy of Sciences, Szeged, Hungary. ${ }^{3}$ Department of Genetics, Cell- and Immunobiology, Semmelweis University, Budapest, Hungary. ${ }^{4}$ Béres Pharmaceuticals Ltd, Budapest, Hungary. ${ }^{5}$ Pharmahungary Group, Szeged, Hungary. ${ }^{6}$ Department of Pharmacology and Pharmacotherapy, Semmelweis University, Budapest, Hungary.

\section{Received: 10 April 2015 Accepted: 17 June 2015}

\section{Published online: 28 June 2015}

\section{References}

1. Global status report on noncommunicable diseases 2014. Geneva, WHO, 2014. http://www.who.int/global-coordination-mechanism/publications/ global-status-report-ncds-2014-eng.pdf.

2. Zimmet P, Alberti KG, Shaw J. Global and societal implications of the diabetes epidemic. Nature. 2001;414:782-7.

3. Wild S, Roglic G, Green A, Sicree R, King H. Global prevalence of diabetes: estimates for the year 2000 and projections for 2030. Diabetes Care. 2004:27:1047-53.

4. Astrup A, Finer N. Redefining type 2 diabetes: 'diabesity' or 'obesity dependent DM'? Obes Rev. 2000;1:57-9.

5. Whiting DR, Guariguata L, Weil C, Shaw J. IDF diabetes atlas: global estimates of the prevalence of diabetes for 2011 and 2030. Diabetes Res Clin Pract. 2011;94:311-2

6. Li K, Kaaks R, Linseisen J, Rohrmann S. Vitamin/mineral supplementation and cancer, cardiovascular, and all-cause mortality in a German prospective cohort (EPIC-Heidelberg). Eur J Nutr. 2012;51:407-13.

7. Bailey RL, Fulgoni VL, Keast DR, Dwyer JT. Examination of vitamin intakes among US adults by dietary supplement use. J Acad Nutr Diet. 2012;112:657-63.
8. Song $Y, X u$ Q, Park Y, Hollenbeck A, Schatzkin A, Chen H. Multivitamins, individual vitamin and mineral supplements, and risk of diabetes among older U.S. adults. Diabetes Care. 2011;34:108-14.

9. Radimer K, Bindewald B, Hughes J, Ervin B, Swanson C, Picciano MF. Dietary supplement use by US adults: data from the National Health and Nutrition Examination Survey, 1999-2000. Am J Epidemiol. 2004;160:339-49.

10. Rock CL. Multivitamin-multimineral supplements: who uses them? Am J Clin Nutr. 2007;85:277S-9S

11. Beitz R, Mensink GB, Fischer $B$, Thamm M. Vitamins-dietary intake and intake from dietary supplements in Germany. Eur J Clin Nutr. 2002;56:539-45.

12. Csont T, Sárközy M, Szűcs G, Szücs C, Bárkányi J, Bencsik P, et al. Effect of a multivitamin preparation supplemented with phytosterol on serum lipids and infarct size in rats fed with normal and high cholesterol diet. Lipids Health Dis. 2013;12:138.

13. Garaiova I, Muchova J, Nagyova Z, Mislanova C, Oravec S, Dukat A, et al. Effect of a plant sterol, fish oil and B vitamin combination on cardiovascular risk factors in hypercholesterolemic children and adolescents: a pilot study. Nutr J. 2013;12:7

14. Sárközy M, Fekete V, Szűcs G, Török S, Szűcs C, Bárkányi J, et al. Anti-diabetic effect of a preparation of vitamins, minerals and trace elements in diabetic rats: a gender difference. BMC Endocr Disord. 2014;14:72.

15. Kaur B, Henry J. Micronutrient status in type 2 diabetes: a review. Adv Food Nutr Res. 2014;71:55-100

16. Zabłocka-Słowińska K, Dzielska E, Gryszkin I, Grajeta H. Dietary supplementation during diabetes therapy and the potential risk of interactions. Adv Clin Exp Med. 2014;23:939-46.

17. McClelland AD, Kantharidis P. MicroRNA in the development of diabetic complications. Clin Sci (Lond). 2014;126:95-110.

18. Asrih M, Steffens S. Emerging role of epigenetics and miRNA in DCM. Cardiovasc Pathol. 2013:22:117-25.

19. Glyn-Jones S, Song S, Black MA, Phillips AR, Choong SY, Cooper GJ. Transcriptomic analysis of the cardiac left ventricle in a rodent model of diabetic cardiomyopathy: molecular snapshot of a severe myocardial disease. Physiol Genomics. 2007;28:284-93.

20. Wang N, Yang C, Xie F, Sun L, Su X, Wang Y, et al. Gadd45a: a novel diabetes-associated gene potentially linking diabetic cardiomyopathy and baroreflex dysfunction. PLoS One. 2012;7:e49077.

21. Diao $X$, Shen E, Wang $X$, Hu B. Differentially expressed microRNAs and their target genes in the hearts of streptozotocin-induced diabetic mice. Mol Med Rep. 2011;4:633-40.

22. D'Souza A, Howarth FC, Yanni J, Dobrzynski H, Boyett MR, Adeghate E, et al. Chronic effects of mild hyperglycaemia on left ventricle transcriptional profile and structural remodelling in the spontaneously type 2 diabetic Goto-Kakizaki rat. Heart Fail Rev. 2014;19:65-74.

23. Sárközy M, Zvara A, Gyémánt N, Fekete V, Kocsis GF, Pipis J, et al. Metabolic syndrome influences cardiac gene expression pattern at the transcript leve in male ZDF rats. Cardiovasc Diabetol. 2013;12:16.

24. Patel SB, Santani D, Patel V, Shah M. Anti-diabetic effects of ethanol extract of Bryonia laciniosa seeds and its saponins rich fraction in neonatally STZinduced diabetic rats. Pharmacognosy Res. 2015;7:92-9.

25. Andrade-Cetto A, Revilla-Monsalve $\mathrm{C}$, Wiedenfeld $\mathrm{H}$. Hypoglycemic effect of Tournefortia hirsutissima L. on n-STZ diabetic rats. J Ethnopharmacol. 2007;112:96-100

26. Li L, Yi Z, Seno M, Kojima I. Activin A and betacellulin. Effect on regeneration of pancreatic beta-cells in neonatal STZ-treated rats. Diabetes. 2004;53:608-15.

27. Thyssen S, Arany E, Hill DJ. Ontogeny of regeneration of beta-cells in the neonatal rat after treatment with STZ. Endocrinology. 2006;147:2346-56.

28. Patel BM, Raghunathan S, Porwal U. Cardioprotective effects of magnesium valproate in type 2 diabetes mellitus. Eur J Pharmacol. 2014;728:128-34.

29. Patel BM, Bhadada SV. Type 2 diabetes-induced cardiovascular complications: comparative evaluation of spironolactone, atenolol, metoprolol, ramipril and perindopril. Clin Exp Hypertens. 2014;36:340-7.

30. Patel BM, Kakadiya J, Goyal RK, Mehta AA. Effect of spironolactone on cardiovascular complications associated with type-2 diabetes in rats. Exp Clin Endocrinol Diabetes. 2013:121:441-7.

31. Goyal BR, Parmar K, Goyal RK, Mehta AA. Beneficial role of telmisartan on cardiovascular complications associated with STZ-induced type 2 diabetes in rats. Pharmacol Rep. 2011;63:956-66.

32. Abebe W, Mozaffari MS. Vascular reactivity changes in glucose-intolerant rat. J Cardiovasc Pharmacol. 2007:50:590-7. 
33. Sartoretto JL, Oliveira MA, Nigro D, Carvalho MH, Tostes RC, Fortes ZB. Constrictor responses to noradrenaline, hemodynamic profile, and superoxide levels measured by hydroethidine oxidation in diabetic rats. Biol Pharm Bull. 2007:30:1938-42.

34. Huisamen B, van Zyl M, Keyser A, Lochner A. The effects of insulin and betaadrenergic stimulation on glucose transport, glut 4 and PKB activation in the myocardium of lean and obese non-insulin dependent diabetes mellitus rats. Mol Cell Biochem. 2001:223:15-25.

35. Kocsis GF, Sárközy M, Bencsik P, Pipicz M, Varga ZV, Pálóczi J, et al. Preconditioning protects the heart in a prolonged uremic condition. Am J Physiol Heart Circ Physiol. 2012;303:H1229-36.

36. Ferdinandy P, Szilvássy Z, Csont T, Csonka C, Nagy E, Koltai M, et al. Nitroglycerin-induced direct protection of the ischaemic myocardium in isolated working hearts of rats with vascular tolerance to nitroglycerin. $\mathrm{Br}$ J Pharmacol. 1995;115:1129-31.

37. Csont T, Páli T, Szilvássy Z, Ferdinandy P. Lack of correlation between myocardial nitric oxide and cyclic guanosine monophosphate content in both nitrate-tolerant and -nontolerant rats. Biochem Pharmacol. 1998:56:1139-44

38. Bell RM, Yellon DM. Conditioning the whole heart-not just the cardiomyocyte. J Mol Cell Cardiol. 2012;53:24-32.

39. Cury DP, Dias FJ, Sosthenes MC, Dos Santos Haemmerle CA, Ogawa K, et al. Morphometric, quantitative, and three-dimensional analysis of the heart muscle fibers of old rats: Transmission electron microscopy and highresolution scanning electron microscopy methods. Microsc Res Tech. 2013;76:184-95.

40. Bugger $\mathrm{H}$, Abel ED. Molecular mechanisms of DCM. Diabetologia. 2014;57:660-71.

41. Dhalla NS, Takeda N, Rodriguez-Leyva D, Elimban V. Mechanisms of subcellular remodeling in heart failure due to diabetes. Heart Fail Rev. 2014;19:87-99.

42. Wang J, Song Y, Wang Q, Kralik PM, Epstein PN. Causes and characteristics of DCM. Rev Diabet Stud. 2006:3:108-17.

43. Ren J, Yang M, Qi G, Zheng J, Jia L, Cheng J, et al. Proinflammatory protein CARD9 is essential for infiltration of monocytic fibroblast precursors and cardiac fibrosis caused by Angiotensin II infusion. Am J Hypertens. 2011;24:701-7.

44. Rokosh DG, Stewart AF, Chang KC, Bailey BA, Karliner JS, Camacho SA, et al. Alpha1-adrenergic receptor subtype mRNAs are differentially regulated by alpha1-adrenergic and other hypertrophic stimuli in cardiac myocytes in culture and in vivo. Repression of alpha1B and alpha1D but induction of alpha1C. J Biol Chem. 1996;271:5839-43.

45. Messner B, Kern J, Wiedemann D, Schwaiger S, Türkcan A, Ploner C, et al. 5Methoxyleoligin, a lignan from Edelweiss, stimulates CYP26B1-dependent angiogenesis in vitro and induces arteriogenesis in infarcted rat hearts in vivo. PLoS One. 2013:8:e58342.

46. Reijntjes S, Blentic A, Gale E, Maden M. The control of morphogen signalling: regulation of the synthesis and catabolism of retinoic acid in the developing embryo. Dev Biol. 2005;285:224-37.

47. Jia LG, Donnet C, Bogaev RC, Blatt RJ, McKinney CE, Day KH, et al. Hypertrophy, increased ejection fraction, and reduced Na-K-ATPase activity in phospholemman-deficient mice. Am J Physiol Heart Circ Physiol. 2005;288:H1982-8.

48. Pavlovic D, Fuller W, Shattock MJ. Novel regulation of cardiac Na pump via phospholemman. J Mol Cell Cardiol. 2013;61:83-93.

49. Boguslavskyi A, Pavlovic D, Aughton K, Clark JE, Howie J, Fuller W, et al. Cardiac hypertrophy in mice expressing unphosphorylatable phospholemman. Cardiovasc Res. 2014;104:72-82.

50. Shichi D, Kikkawa EF, Ota M, Katsuyama Y, Kimura A, Matsumori A, et al. The haplotype block, NFKBIL1-ATP6V1G2-BAT1-MICB-MICA, within the class III-class I boundary region of the human major histocompatibility complex may control susceptibility to hepatitis C virus-associated dilated cardiomyopathy. Tissue Antigens. 2005;66:200-8.

51. Hu X, Sui X, Li L, Huang X, Rong R, Su X, et al. Protocadherin 17 acts as a tumour suppressor inducing tumour cell apoptosis and autophagy, and is frequently methylated in gastric and colorectal cancers. J Pathol. 2013;229:62-73.

52. Fritz RD, Varga Z, Radziwill G. CNK1 is a novel Akt interaction partner that promotes cell proliferation through the Akt-FoxO signalling axis. Oncogene. 2010:29:3575-82

53. Lim J, Zhou M, Veenstra TD, Morrison DK. The CNK1 scaffold binds cytohesins and promotes insulin pathway signaling. Genes Dev. 2010;24:1496-506
54. Lee SH, Demeterco C, Geron I, Abrahamsson A, Levine F, Itkin-Ansari P. Islet specific Wnt activation in human type II diabetes. Exp Diabetes Res. 2008;2008:728763.

55. Xue W, Liu Y, Zhao J, Cai L, Li X, Feng W. Activation of HIF-1 by metallothionein contributes to cardiac protection in the diabetic heart. Am J Physiol Heart Circ Physiol. 2012;302:H2528-35.

56. Feng W, Benz FW, Cai J, Pierce WM, Kang YJ. Metallothionein disulfides are present in metallothionein-overexpressing transgenic mouse heart and increase under conditions of oxidative stress. J Biol Chem. 2006;281:681-7.

57. Interleukin-6 Receptor Mendelian Randomisation Analysis (IL6R MR) Consortium. The interleukin- 6 receptor as a target for prevention of coronary heart disease: a mendelian randomisation analysis. Lancet. 2012;379:1214-24.

58. Palomer X, Salvadó L, Barroso E, Vázquez-Carrera M. An overview of the crosstalk between inflammatory processes and metabolic dysregulation during diabetic cardiomyopathy. Int J Cardiol. 2013;68:3160-72.

59. Wu ML, Ho YC, Yet SF. A central role of heme oxygenase-1 in cardiovascular protection. Antioxid Redox Signal. 2011;15:1835-46.

60. Douglas KT. Mechanism of action of glutathione-dependent enzymes. Adv Enzymol Relat Areas Mol Biol. 1987:59:103-67.

61. L'Ecuyer T, Allebban Z, Thomas R, Vander HR. Glutathione S-transferase overexpression protects against anthracycline-induced H9C2 cell death. Am J Physiol Heart Circ Physiol. 2004;286:H2057-64.

62. Puskas LG, Nagy ZB, Giricz Z, Onody A, Csonka C, Kitajka K, et al. Cholesterol diet-induced hyperlipidemia influences gene expression pattern of rat hearts: a DNA microarray study. FEBS Lett. 2004;562:99-104.

63. Zhang S, Liu H, Amarsingh GV, Cheung CC, Hogl S, Narayanan U, et al. Diabetic cardiomyopathy is associated with defective myocellular copper regulation and both defects are rectified by divalent copper chelation. Cardiovasc Diabetol. 2014;13:100.

64. Miao X, Wang Y, Sun J, Sun W, Tan Y, Cai L, et al. Zinc protects against diabetes-induced pathogenic changes in the aorta: roles of metallothionein and nuclear factor (erythroid-derived 2)-like 2. Cardiovasc Diabetol. 2013;12:54.

65. Li B, Tan Y, Sun W, Fu Y, Miao L, Cai L. The role of zinc in the prevention of diabetic cardiomyopathy and nephropathy. Toxicol Mech Methods. 2013;23:27-33

66. Csont T, Murlasits Z, Ménesi D, Kelemen JZ, Bencsik P, Pipicz M, et al. Tissuespecific gene expression in rat hearts and aortas in a model of vascular nitrate tolerance. J Cardiovasc Pharmacol. 2015;65:485-93.

67. Park HK, Ahima RS. Resistin in rodents and humans. Diabetes Metab J. 2013:37:404-14.

68. Gragnoli C. Hypothesis of the neuroendocrine cortisol pathway gene role in the comorbidity of depression, type 2 diabetes, and metabolic syndrome. Appl Clin Genet. 2014;7:43-53.

69. Fang P, Sun J, Wang X, Zhang Z, Bo P, Shi M. Galanin participates in the functional regulation of the diabetic heart. Life Sci. 2013;92:628-32.

70. Marino G, Zanghì A. Activins and inhibins: expression and role in normal and pathological canine reproductive organs: a review. Anat Histol Embryol. 2013;42:1-8

71. Rayman MP. Selenium and human health. Lancet. 2012;379:1256-68.

72. Cameron FJ, Wherrett DK. Care of diabetes in children and adolescents: controversies, changes, and consensus. Lancet. 2015;385:2096-106.

73. Faragó N, Kocsis GF, Fehér LZ, Csont T, Hackler Jr L, Varga-Orvos Z, et al. Gene and protein expression changes in response to normoxic perfusion in mouse hearts. J Pharmacol Toxicol Methods. 2008:57:145-54.

74. Gaziano JM, Sesso HD, Christen WG, Bubes V, Smith JP, MacFadyen J, et al. Multivitamins in the prevention of cancer in men: the Physicians' Health Study II randomized controlled trial. JAMA. 2012;308:1871-80. 